\title{
非水体系锂-空气电池研究进展
}

\author{
吴爱明 ${ }^{1}$ 夏国锋 ${ }^{1}$ 沈水云 ${ }^{1} \quad$ 殷洁炜 $^{1} \quad$ 毛 亚 $^{2}$ \\ 白清友 ${ }^{2}$ 解晶荣 ${ }^{2}$ 章俊良 ${ }^{1, *}$ \\ ( ${ }^{1}$ 上海交通大学燃料电池研究所, 上海 200240; ${ }^{2}$ 上海空间电源研究所, 上海航天技术研究院, 上海 200233)
}

\begin{abstract}
摘要: 锂-空气电池是目前已知具有最高能量密度的二次电池, 有望成为未来电动汽车的动力电源。由于其 能量密度高、环境友好以及成本较低, 成为广大科研工作者研究的热点, 在过去二十年间与之有关的研究已 经在反应机理、电极结构、催化剂及电解液等各方面都取得了很大进展, 但受诸多因素限制, 其实用化仍然 任重道远。本文总结了近几年来非水体系锂-空气电池在反应机理、正极材料、催化剂、电解液以及锂负极 等方面的最新研究进展, 并在此基础上展望其未来的发展方向。
\end{abstract}

关键词: 锂-空气电池; 反应机理; 正极材料; 锂负极; 电解液

中图分类号 : 0646

\section{Recent Progress in Non-Aqueous Lithium-Air Batteries}

\author{
WU Ai-Ming ${ }^{1} \quad$ XIA Guo-Feng ${ }^{1} \quad$ SHEN Shui-Yun ${ }^{1} \quad$ YIN Jie-Wei ${ }^{1} \quad$ MAO Ya ${ }^{2}$ \\ BAI Qing-You ${ }^{2} \quad$ XIE Jing-Ying ${ }^{2} \quad$ ZHANG Jun-Liang ${ }^{1, *}$ \\ ('Institute of Fuel Cells, Shanghai Jiao Tong University, Shanghai 200240, P. R. China;
}

${ }^{2}$ Shanghai Institute of Space Power-Sources, Shanghai Academy of Spaceflight Technology, Shanghai 200233, P. R. China)

\begin{abstract}
As a secondary battery, the Li-air battery has the highest theoretical specific energy and has been considered as one of the most promising power sources for electric vehicles. The Li-air battery based on organic electrolyte has become a topic of interest owing to its excellent theoretical energy density, environmental friendliness and low cost. During the past 20 years, much progress has been made in the development of the reaction mechanism, cathode structure, catalyst and electrolyte materials. But there are still many obstacles to overcome before its practical applications. In this paper, we review some of the latest progress in the research on the reaction mechanism, cathode materials, catalysts, electrolytes, as well as the lithium anode. Future research and development prospects are also discussed.
\end{abstract}

Key Words: Li-air battery; Reaction mechanism; Cathode material; Lithium anode; Electrolyte

\section{1 引言}

锂-空气电池是目前已知具有最高理论能量密 度的二次电池, 以 $1 \mathrm{~kg}$ 锂计算, 其理论能量密度 高达 $11400 \mathrm{Wh} \cdot \mathrm{kg}^{-1}$, 完全可以与汽油相媲美, 如
果计算氧气的质量, 其理论能量密度也依然高达 $3458 \mathrm{Wh} \cdot \mathrm{kg}^{-1}$, 远高于目前所有的锂离子电池体 系。锂-空气电池的概念最早由 Littauer 等'在 1976 年提出, 但当时只是作为一次电池来研究。直到

Received: March 28, 2016; Revised: May 25, 2016; Published on Web: May 26, 2016.

${ }^{*}$ Corresponding author. Email: junliang.zhang@sjtu.edu.cn; Tel: +86-21-3420-7439.

The project was supported by the New Faculty Startup Fund of Shanghai Jiao Tong University, China (14X10040061), National Key Basic Research Program of China (973) (2014CB932303), and SJTU-UM Project (15X120010002).

上海交通大学青年人才科研能力培育专项(14X10040061), 国家重点基础研究发展规划项目(973) (2014CB932303)和上海交通大学-密西根大 学国际合作项目(15X120010002)资助 
1996年, Abraham 和 Jiang ${ }^{2}$ 才成功地实现了 3 次充/ 放电循环, 并提出了锂-空气电池的工作机理 $(2 \mathrm{Li}+$

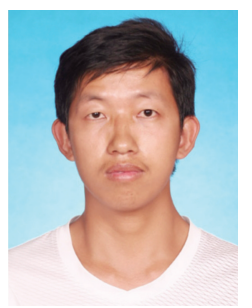

吴爱明, 1990 年生。上海交通大 学机械与动力工程学院 2014 级硕 博连读研究生, 研究方向: 锂空 气电池。

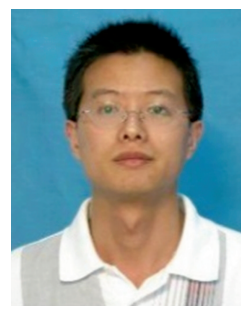

夏国锋, 2013年于哈尔滨工业大学 化工学院获得博士学位, 2015年于 上海交通大学博士后出站, 现为上 海交通大学机械与动力工程学院燃 料电池研究所助理研究员。主要从 事锂离子电池、锂空气电池以及质 子交换膜燃料电池的研究与开发。
$\left.\mathrm{O}_{2} \rightleftharpoons \mathrm{Li}_{2} \mathrm{O}_{2}\right)$ 。2006 年 Bruce 等 ${ }^{3}$ 进一步实现了 50 次 的充/放电循环, 并在放电产物中成功地检测出了 过氧化锂 $\left(\mathrm{Li}_{2} \mathrm{O}_{2}\right)$, 这一重要结果使得锂-空气电池 进入了快速发展的阶段。

在已开发的多种锂-空气电池体系中, 水体系 锂-空气电池、全固态锂-空气电池、混合体系锂空气电池的研究工作进行的相对较少 ${ }^{4-6}$, 目前已 取得的大多数研究成果都是基于非水体系的锂-空 气电池, 因此, 本文将围绕非水体系锂-空气电池

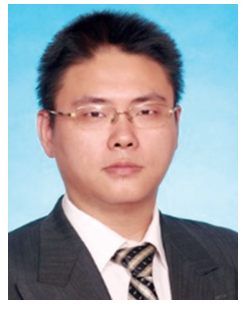

殷洁炜，1984 年生。2015 毕业于 上海交通大学应用化学专业获得博 士学位。目前就职于上海交通大学 机械与动力工程学院燃料电池研究 所, 担任助理研究员兼实验室主 任。主要从事质子交换膜燃料电池 电堆和电堆关键材料的开发, 固体氧化物燃料电 池电极材料以及锂空气电池相关催化剂的研究。

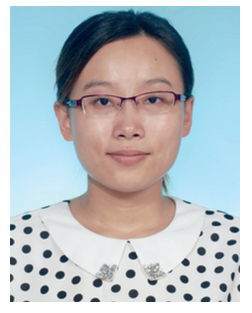

沈水云, 2012 年毕业于香港科技 大学机械工程专业获得博士学位。 现为上海交通大学机械与动力工程 学院燃料电池研究所讲师、博导。 主要从事电催化、纳米材料、质子 交换膜燃料电池和锂空气电池的研 究与开发。

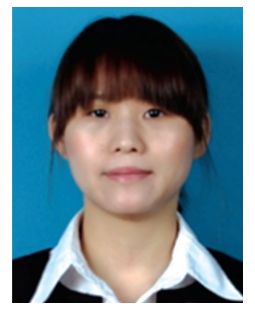

毛亚, 博士，2013 年毕业于中国 科学院物理研究所清洁能源实验 室凝聚态物理专业。毕业后进入 上海空间电源研究所, 主要从事 锂离子电池、下一代化学电源相 关基础研究。

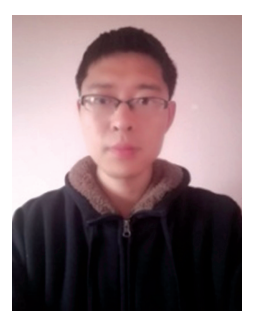

白清友, 1988年生。硕士学位, 上 海空间电源研究所电化学中心研究 师, 工程师。主要研究领域为电化 学材料与储能元器件, 包括安全性 锂离子电池、高比能锂空气电池。

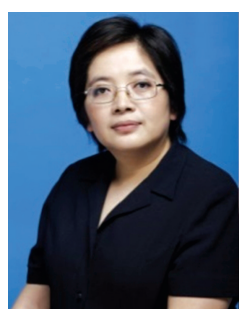

解晶莹, 工学博士, 上海市动力与 储能电池系统工程技术中心主任, 中国电化学会及固态离子学会理 事, 《电源技术》编委, 上海空间 电源研究所教授、研究员、博导。 长期从事化学电源相关材料、器件 及系统工作的研究与开发。

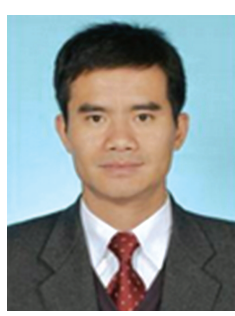

章俊良, 1994 年和 1997 年毕业于 上海交通大学, 分别获学士和硕士 学位, 2005 年于美国纽约州立大学 石溪分校获博士学位。2009年获得 上海市 “东方学者”特聘教授。现 任上海交通大学机械与动力工程学 院副院长, 燃料电池研究所所长, 上海交通大学 “致远” 讲席教授, 国家 “千人计划” 暨首批上海 “千人计划” 特聘专家, Electrocatalysis 国际期刊 编委。多年来一直从事电化学、燃料电池、锂空 气电池、锂离子电池及催化剂方面的研究, 并取 得多项突破性成果。 
的反应机理、正极材料、电解液及锂负极等方面 的最新研究成果展开综述。

\section{2 非水体系锂-空气电池反应机理}

非水系锂-空气电池以金属锂为负极, 多孔空 气电极为正极, 含有锂盐的有机溶液为电解液。 关于锂-空气电池的反应机理, 大多数的研究工作 者比较认同是如式(1)-(7)所示的表面电化学过 程, 即放电过程中, 锂被氧化生成 $\mathrm{Li}^{+}, \mathrm{Li}^{+}$再由电 解液传输至正极, 而锂失去的电子则由外电路传 递到阴极。同时, 氧气接受由外电路传来的电 子, 在正极发生氧还原反应(oxygen reduction reaction, ORR) 还原为 $\mathrm{O}_{2}^{-}, \mathrm{O}_{2}^{-}$与电解液中的 $\mathrm{Li}^{+}$结合后 形成 $\mathrm{LiO}_{2}$, 式(2) 可分解为式(6)和(7)两步是形成 $\mathrm{LiO}_{2}$ 的过程。式(3)和(4)是形成最终产物 $\mathrm{Li}_{2} \mathrm{O}_{2}$ 的两 种途径, 式(3)是一个电化学过程, 式(4) 是 $\mathrm{LiO}_{2}$ 歧 化分解形成 $\mathrm{Li}_{2} \mathrm{O}_{2}$ 的过程。在充电过程中, $\mathrm{Li}_{2} \mathrm{O}_{2}$ 发 生氧析出反应 (oxygen evolution reaction, OER), 最终分解生成 $\mathrm{O}_{2}$ 和 $\mathrm{Li}^{+}, \mathrm{Li}^{+}$在负极表面得到电子被 还原为金属锂 ${ }^{7-11}$ 。

$$
\begin{array}{ll}
2 \mathrm{Li} \rightleftharpoons 2\left(\mathrm{Li}^{+}+\mathrm{e}^{-}\right) & \text {(阳极) } \\
\mathrm{Li}^{+}+\mathrm{e}^{-}+\mathrm{O}_{2} * \rightleftharpoons \mathrm{LiO}_{2}{ }^{*} & \text { (阴极) } \\
\mathrm{Li}^{+}+\mathrm{e}^{-}+\mathrm{LiO}_{2} * \rightleftharpoons \mathrm{Li}_{2} \mathrm{O}_{2} * & \text { (阴极) } \\
\mathrm{LiO}_{2}{ }^{*}+\mathrm{LiO}_{2}{ }^{*} \rightleftharpoons \mathrm{Li}_{2} \mathrm{O}_{2}{ }^{*}+\mathrm{O}_{2} & \text { (阴极) } \\
\mathrm{e}^{-}+\mathrm{O}_{2} \rightarrow \mathrm{O}_{2}^{-} & \\
\mathrm{O}_{2}^{-}+\mathrm{Li}^{+} \rightarrow \mathrm{LiO}_{2} \rightarrow \mathrm{LiO}_{2}{ }^{*} &
\end{array}
$$

由于上述机理中的放电中间产物 $\mathrm{LiO}_{2}$ 非常活 泼, 对于 $\mathrm{LiO}_{2}$ 的检测一直以来是一个很困难的问 题, 随着测试表征手段的提高, 证实中间产物 $\mathrm{LiO}_{2}$ 确实是存在的。Peng 等 ${ }^{10}$ 通过循环伏安 $(\mathrm{CV})$ 测 试和表面增强拉曼光谱(SERS)表征在放电产物中 检测到了 $\mathrm{LiO}_{2}$ 的存在, Luntz等7借助微分电化学质 谱(DEMS) 发现在低于 $4.0 \mathrm{~V}$ 以下的充/放电过程 中, 参与反应的电子数与充/放电过程中生成/消耗 的 $\mathrm{O}_{2}$ 的物质的量之比都接近 2 , 而式(2)中电子与氧 气的物质的量比却为 1 , 所以质疑式(2)中的反应历 程, 但是这无法否定 $\mathrm{LiO}_{2}$ 的存在, Amine 等 ${ }^{12}$ 以活 性炭为空气电极通过低温条件下 $(T=100 \mathrm{~K})$ 的拉曼 (Raman) 测试检测到 $\mathrm{LiO}_{2}$ 的存在, 最近 $\mathrm{Lu}^{\text {等 }}{ }^{13}$ 借助 高能 X 射线衍射(HE-XRD)、原位 DEMS 测试手段 以及拉曼测试对 $\mathrm{Ir}$ 修饰的还原氧化石墨烯 $(\mathrm{rGO})$ 电 极放电产物进行分析, HE-XRD 和 Raman 检测发 现放电产物主要是 $\mathrm{LiO}_{2}, \mathrm{DEMS}$ 结果表明电子 $\left(\mathrm{e}^{-}\right)$
与氧气 $\left(\mathrm{O}_{2}\right)$ 的物质的量比为 1 , 这进一步证实了式 (2) 的存在, 即锂-空气电池放电过程中确实存在 $\mathrm{LiO}_{2}$ 。

另外, 上述机理并没有充分考虑到水分子的 作用和影响。在现有技术条件下, 无论是电解 液、隔膜、电极都会或多或少吸附一定的水份, 并最终带入到电池内。而已有实验表明微量的水 份都会改变放电产物 $\mathrm{Li}_{2} \mathrm{O}_{2}$ 的形貌和颗粒大小 ${ }^{14}$, 甚 至改变放电产物, Grey 等 ${ }^{15}$ 以大孔石墨烯为电极向 电解液中加入了 $0.05 \mathrm{~mol} \cdot \mathrm{L}^{-1}$ 的 $\mathrm{LiI}$, 结果放电产物 主要是 $\mathrm{LiOH}, \mathrm{LiI}$ 在催化分解 $\mathrm{LiOH}$ 的过程中起到 非常重要的作用, 形成 $\mathrm{LiOH}$ 的 $\mathrm{H}$ 可能来自于电解 液、石墨烯电极和电极或隔膜等带入的水。说明 这些水份已经对电池的充/放电过程产生了影响。 因此, 关于锂-空气电池的运行机理, 还需要继续 开展相应的研究工作, 配合更为先进的测试仪器 和方法来厘清, 这对于进一步提高锂-空气电池性 能和推进其实际化具有重要意义。

\section{3 空气电极关键材料}

锂-空气电池是一个建立在固态电极, 液态电 解液和氧气三相界面上的一个电化学反应过程, 这使得锂-空气电池体系比传统的锂离子电池更加 复杂。由于非水系锂-空气电池的放电产物为不溶 性的 $\mathrm{Li}_{2} \mathrm{O}_{2}$, 随着放电过程的进行, 放电产物会逐 渐积累堵塞电极孔道, 最终导致反应提前终止 ${ }^{16}$ 。 因此, 在锂-空气电池中, 为了实现锂-空气电池的 高充放电容量特性, 首先, 应选择合适的电极材 料和电极结构, 其次, 空气电极还应具有适当的 孔径和孔容 ${ }^{17,18}$, 以及具有较大的比表面积 ${ }^{19}$, 第 三, 空气电极应具加入一定比例的具有较高 ORR 和 OER 活性的催化剂。

\section{1 碳电极材料及非碳电极材料}

由于具有导电性高、氧吸附能力强、氧还原 活性好、成本低等优良性质 ${ }^{20,21}$, 因此碳电极在锂空气电池中的应用十分广泛, 常见的有炭黑、介 孔碳、碳纳米管、碳纤维及石墨烯等。

Kang 等 ${ }^{22}$ 以乙炔气为原料通过化学气相沉积 成功合成了碳纳米管纤维, 作为锂-空气电池的正 极材料, 在电流密度为 $2 \mathrm{~A} \cdot \mathrm{g}^{-1}$, 限容 $1000 \mathrm{mAh}$. $\mathrm{g}^{-1}$ 的条件下, 循环超过 60 次, 表现出优良的循环 性能。这是由于碳纳米管纤维具有独特的大孔网 络结构, 改善了气体在电极中的扩散以及电解液 
的传输, 同时也为放电产物 $\mathrm{Li}_{2} \mathrm{O}_{2}$ 的沉积提供了足 够的存储空间。Zhang 等 ${ }^{23}$ 将制备的分层多孔石墨 烯纳米片用作锂-空气电池的空气电极, 首次放电 比容量高达 $15000 \mathrm{mAh} \cdot \mathrm{g}^{-1}$, 原因在于这种多孔石 墨烯纳米片具有特殊的双重孔道结构 (见图 1), 外 层大孔道有利于氧气的高效传输, 而壁上的小孔 可以提供较高的三相反应界面, 有利于电化学反 应的进行，从而使其具有很高的催化活性。Zhang 等 ${ }^{24}$ 将碳纳米管上引入含氧官能团后作为锂-空气 电池的正极材料, 研究发现引入的含氧官能团尽 管在一定程度上降低了材料的导电性，但是可以 大大增加电极催化反应活性位点数量, 增加碳纳 米管的 ORR 催化活性。当碳纳米管上氧的原子分 数达到 $6.0 \%$ (CNTs- $6.0 \%)$ 时, 首圈放电容量就可以 达到 $3200 \mathrm{mAh} \cdot \mathrm{g}^{-1}$, 循环次数超过 70 次, 是纯碳 纳米管 $(\mathrm{CNTs}-0.7 \%)$ 的 3 倍左右。

此外, Zhou等 ${ }^{25}$ 合成的多孔网状的碳化细菌纤 维素 (CBC), Wang 等 ${ }^{26}$ 制备的立方介孔碳 $(\mathrm{MCCs}), \mathrm{Chen}$ 等 ${ }^{27}$ 制备的氮参杂和硫参杂三维多孔 石墨烯, $\mathrm{Wu}$ 等 ${ }^{28}$ 成功制备的 $\mathrm{Fe} 、 \mathrm{~N}$ 参杂的竹节状石 墨烯材料，Xia等 ${ }^{29}$ 合成的介孔泡沫碳(MCF-C)等应 用于锂-空气电池都获得了不错的性能。

虽然碳材料具有很多优良的性能, 但是实验 证明, 碳材料在放电过程中会促进电解液分解生
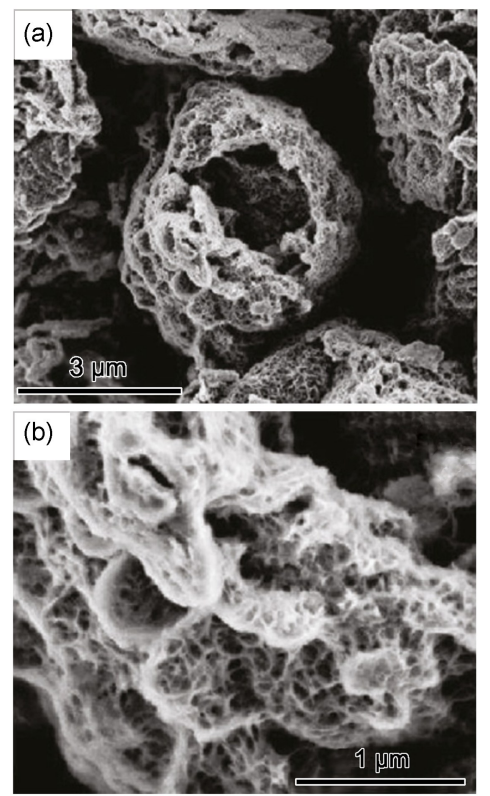

图 1 分层多孔石墨烯的 SEM 图像 ${ }^{23}$

Fig.1 SEM images of the hierarchically porous graphene ${ }^{23}$ (a) large interconnected tunnels;

(b) small nanoscale pores contiguous with the large tunnels
成 $\mathrm{Li}_{2} \mathrm{CO}_{3}$ 和 $\mathrm{LiRCO}_{3}$ 等副产物, 而充电过程中碳材 料自身也会发生分解反应, 从而降低库仑效率, 影响电池性能 ${ }^{30,31}$ 。为了避免碳材料可能带来的上 述副反应, 研究人员也开发了多种新型复合碳电 极和非碳电极材料。Zhang 等 ${ }^{32}$ 通过在碳纺织物 (carbon textile，CT)表面原位生长 $\mathrm{TiO}_{2}$ 纳米线阵列 $\left(\mathrm{TiO}_{2}\right.$ nanowire arrays, $\left.\mathrm{TiO}_{2} \mathrm{NAs}\right)$ 制备自支撑的柔性 $\mathrm{TiO}_{2} \mathrm{NAs} / \mathrm{CT}$ 空气电极, 研究表明由于 $\mathrm{TiO}_{2}$ 纳米线 的覆盖, 能有效减少碳材料与放电产物的接触, 减少副反应，提高电池的循环性能；同时电极表 现出很高的机械强度, 即使在弯曲变形时依然能 够循环超过 100 次。Chen 等 ${ }^{33}$ 以泡沫镍为模板成功 制备成 $\mathrm{Co}_{3} \mathrm{O}_{4} @ \mathrm{TiO}_{2}$ 三维网状结构的一体化电极。 其中 $\mathrm{TiO}_{2}$ 三维网状多孔结构为放电产物提供足够 的存储空间, 同时有利于电解液的传输和氧气的 扩散, 直径为 4-10 nm 的 $\mathrm{Co}_{3} \mathrm{O}_{4}$ 作为催化剂均匀覆 盖在 $\mathrm{TiO}_{2}$ 的表面。在 $200 \mathrm{~mA} \cdot \mathrm{g}^{-1}$ 的电流密度下, 充电电压只有 $3.7 \mathrm{~V}$ 左右, 并且在限容 $1100 \mathrm{mAh}$. $\mathrm{g}^{-1}$ 时可以循环 80 次以上。而 Bruce 等 ${ }^{34}$ 将纳米多孔 金(nanoporous gold, NPG) 电极应用于锂-空气电池, 100 次后依然能维持 $95 \%$ 以上的比容量, 如图 2 所 示。该研究组 ${ }^{35}$ 还制备出更加稳定的空气电极碳化 钛 $\mathrm{TiC}$, 其性能优于碳材料和多孔金电极, 而且重 量是金电极的 $1 / 4$, 循环 100 圈后容量保持率仍在 $98 \%$ 以上，优于多孔金电极的 $95 \%$ (见图 3)。

\section{2 催化剂}

目前, 锂-空气电池的催化剂可分为: 贵金 属、过渡金属氧化物、金属氮化物和碳化物。另 外, 一些氧化-还原电对组成的可溶性催化剂也开 始应用于锂-空气电池。

\section{2 .1 贵金属}

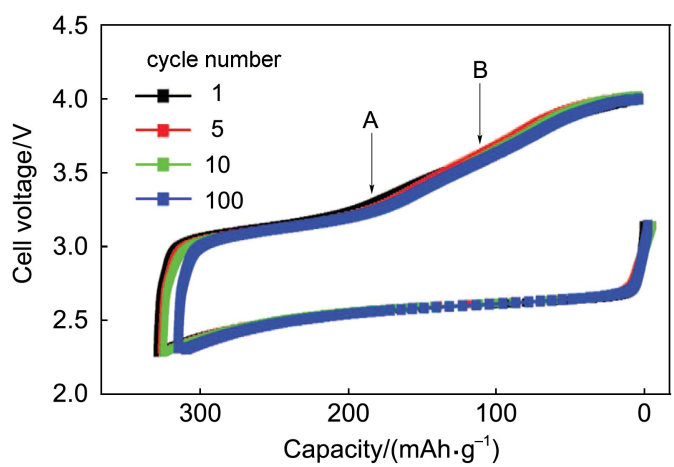

图 2 多孔金电极循环性能 ${ }^{34}$

Fig.2 Cycling performance of the nanoporous gold electrodes $^{34}$ 

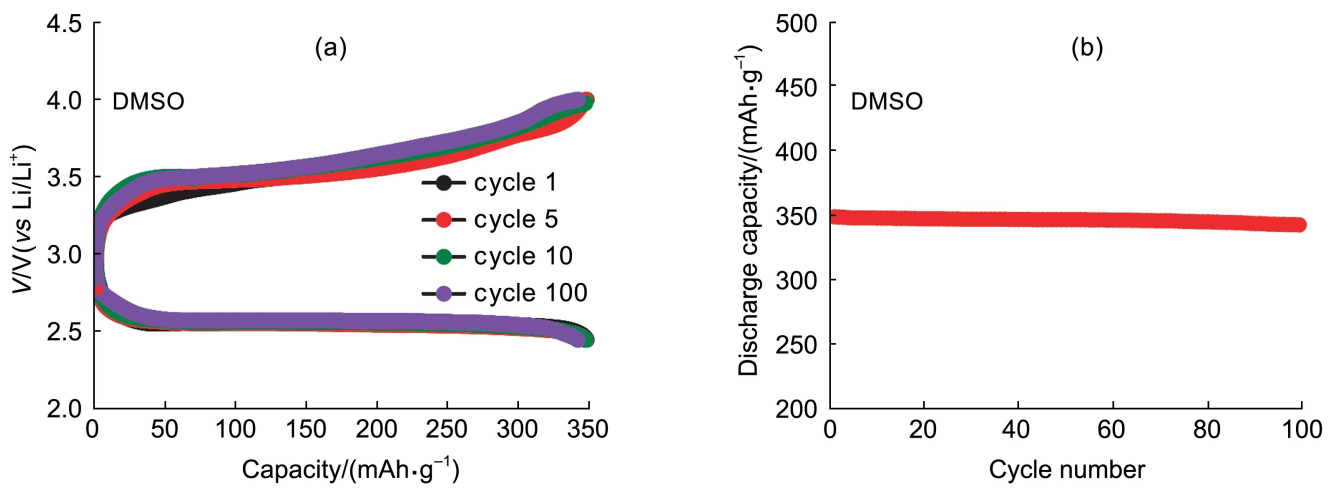

图 $3 \mathrm{TiC}$ 电极的循环性能 ${ }^{35}$

Fig.3 Cycling performance of the TiC electrodes ${ }^{35}$ DMSO: dimethyl sulfoxide

锂-空气电池中贵金属催化剂的研究主要集中 在 $\mathrm{Au} 、 \mathrm{Pt} 、 \mathrm{Pd} 、 \mathrm{Ir}$ 和 $\mathrm{Ru}$ 及其合金或氧化物上。 Shao-Horn 等 ${ }^{36}$ 对贵金属 $\mathrm{Au} 、 \mathrm{Pt}$ 及其 PtAu 合金做了 较为深入的研究, 发现 $\mathrm{Au} / \mathrm{C}$ 催化剂对氧还原反应 (ORR)有很好的催化活性, $\mathrm{Pt} / \mathrm{C}$ 催化剂则对促进氧 析出反应(OER)有显著的催化效果, 而其合金 $\mathrm{PtAu} / \mathrm{C}$ 催化剂具有明显的双催化功能, 充放电过 电压只有 $0.9 \mathrm{~V}$, 从而使 $\mathrm{PtAu} / \mathrm{C}$ 的循环效率达到 $73 \%$, 远高于纯碳电极的 $57 \%$ 。该研究组 ${ }^{37}$ 还进一 步研究了不同贵金属催化剂对 ORR 反应的催化活 性, 以 $0.1 \mathrm{~mol} \cdot \mathrm{L}^{-1} \mathrm{LiClO}_{4} / \mathrm{DME}$ (乙二醇二甲醚) 为 电解液, 当电流密度为 $2 \mu \mathrm{A} \cdot \mathrm{cm}^{-2}$ 时, 对应的氧还 原电位依次为 $\mathrm{Pd}>\mathrm{Pt}>\mathrm{Ru}>\mathrm{Au}>\mathrm{GC}$ (见图 4(a)), 这与锂-空气电池中放电过程早期的 ORR 电位是一 致的(见图 4(b)), 并且此电位与氧在电极表面的吸
附能为火山型关系(见图 4(c)), 说明在有机电解液 体系中贵金属催化剂的 ORR 反应可能存在氧的吸 附过程。

此外, Zhou 等 ${ }^{38}$ 通过溶胶-凝胶法制备核壳结构 的CNT@ $\mathrm{RuO}_{2}$, 与纯 $\mathrm{CNT}$ 电极相比, $\mathrm{CNT} @ \mathrm{RuO}_{2}$ 电 极能够显著降低充电过电压, 提高了充放电效 率, 同时表现出较好的循环性能(见图 5)。Wang 等 ${ }^{39}$ 通过模板法合成的钓 $(\mathrm{Ru})$ 修饰的多孔石墨烯电 极, Zhou 等 ${ }^{40}$ 构建的铱(Ir)修饰的分层多孔石墨烯 $(\mathrm{Ir} @ \mathrm{DHG})$ 材料, Kim 等 ${ }^{41}$ 通过电沉积成功制备的 自支撑 $\mathrm{Au} / \mathrm{Ni}$ 电极, $\mathrm{Chou}$ 等 ${ }^{42}$ 成功合成的 $\mathrm{AgPd}-\mathrm{Pd}$ 合金纳米管材料, Zhang 等 ${ }^{43}$ 通过模板法制备的分 层多孔蜂窝状钯(Pd)修饰的中空碳球(Pd-HSC)以及 该课题组 ${ }^{44}$ 在柔性纸墨电极 (paper-ink cathode, PI 电极)上载金属钉等一系列的贵金属复合材料在锂-
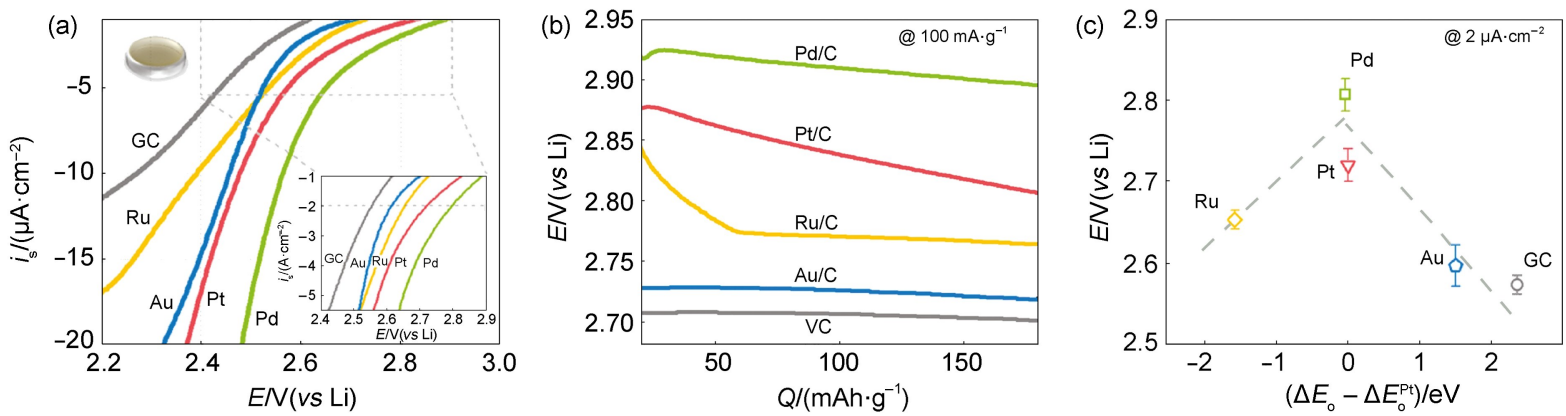

图 4 (a) Pd、Pt、Ru、Au 及 GC 电极的氧还原反应 $(\mathrm{ORR})$ 极化曲线, 电极转速为 $100 \mathrm{r} \cdot \mathrm{min}^{-1}$, 扫描速率为 $20 \mathrm{mV} \cdot \mathrm{s}^{-1}$; (b) $\mathrm{Pd} / \mathrm{C}, \mathrm{Pt} / \mathrm{C}, \mathrm{Ru} / \mathrm{C}, \mathrm{Au} / \mathrm{C}$ 及 $\mathrm{VC}$ 电极在电流密度 $100 \mathrm{~mA} \cdot \mathrm{g}^{-1}$ 时早期的放电曲线; (c)不同电极在电流密度为 $2 \mu \mathrm{A} \cdot \mathrm{cm}^{-2}$ 时的 ORR 电位与相对电极表面氧吸附能 $\left(\Delta E_{0}\right)$ 的关系图(电解液为 $\left.0.1 \mathrm{~mol} \cdot \mathrm{L}^{-1} \mathrm{LiClO}_{4} / \mathrm{DME}\right)^{37}$

Fig.4 Background and IR-corrected specific oxygen reduction reaction (ORR) polarization curves of polycrystalline Pd, Pt,

$\mathrm{Ru}, \mathrm{Au}$, and GC (glassy carbon) surfaces at an electrode speed of $100 \mathrm{r} \cdot \mathrm{min}^{-1}$ and a sweep speed of $20 \mathrm{mV} \cdot \mathrm{s}^{-1}$; (b) initial discharge profiles of $\mathrm{Li}-\mathrm{O}_{2}$ cells of $\mathrm{Pd} / \mathrm{C}, \mathrm{Pt} / \mathrm{C}, \mathrm{Ru} / \mathrm{C}, \mathrm{Au} / \mathrm{C}$, and $\mathrm{VC}$ (vulcan carbon) at a current density of $100 \mathrm{~mA} \cdot \mathrm{g}^{-1}$;

(c) $\mathrm{Li}^{+}$-ORR potentials at a current density of $2 \mu \mathrm{A} \cdot \mathrm{cm}^{-2}$ as a function of calculated oxygen adsorption energy $\left(\Delta E_{\mathrm{o}}\right)$, relative to that of $\mathrm{Pt}$ (the electrolyte is $0.1 \mathrm{~mol} \cdot \mathrm{L}^{-1} \mathrm{LiClO}_{4} / \mathrm{DME}\left(1,2\right.$-dimethoxyethane) ${ }^{37}$ 
(a)

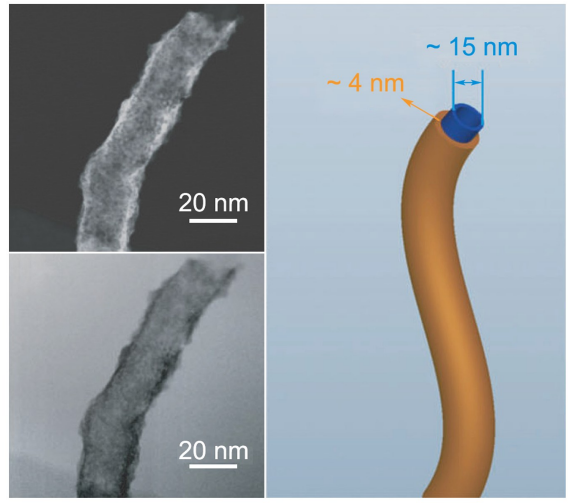

(b)

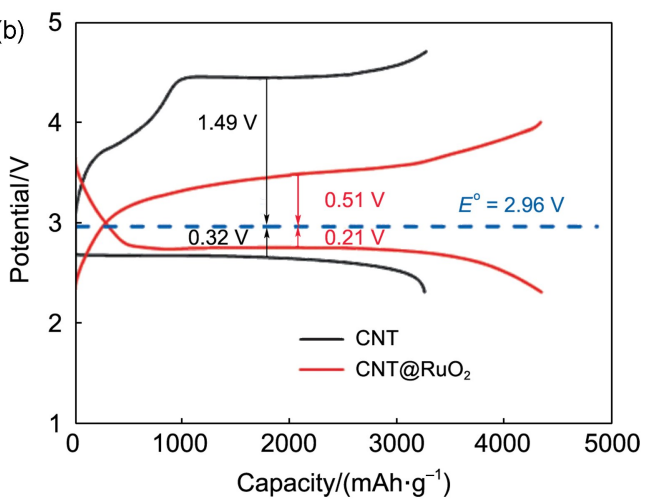

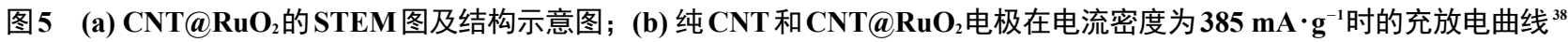

Fig.5 (a) STEM and schematic image of $\mathrm{CNT} @ \mathrm{RuO}_{2}$; (b) discharge/charge profiles of pristine CNT and $\mathrm{CNT} @ \mathrm{RuO}_{2}$ at a current density of $385 \mathrm{~mA} \cdot \mathrm{g}^{-138}$

$E^{\text {: }}$ : theoretical open circuit voltage; CNT: carbon nanotube

空气电池中都表现出良好的催化性能, 这得益于 复合材料特有的多孔结构和贵金属纳米颗粒的催 化作用。

在有机体系的锂-空气电池中, 贵金属 $\mathrm{Pd}$ 、 $\mathrm{Ru} 、 \mathrm{Ir} 、 \mathrm{Au}$ 及其合金、氧化物如 $\mathrm{RuO}_{2}$ 等作为催化 剂, 能明显降低电池的充放电过电位, 起到很好 的催化作用。但是, 贵金属资源比较稀缺, 成本 高, 不利于大规模使用。需要进一步研究开发廉 价高效的双功能催化剂材料来代替贵金属催化剂。

\section{2 .2 过渡金属氧化物}

过渡金属氧化物具有与贵金属相似的催化活 性, 资源比较丰富价格相对便宜, 因此也是目前 研究的热点, 并在锂-空气电池中得到大规模应用。

Bruce 等 ${ }^{45}$ 研究了不同过渡金属氧化物催化剂 对锂-空气电池性能的影响, 研究结果表明 $\mathrm{Fe}_{3} \mathrm{O}_{4}$ 、 $\mathrm{CuO}$ 和 $\mathrm{CoFe}_{2} \mathrm{O}_{4}$ 具有较好的容量保持率, 而 $\mathrm{Co}_{3} \mathrm{O}_{4}$ 作为催化剂时同时具备较高的初始比容量和容量 保持率。该研究组 ${ }^{46}$ 还发现 $\alpha-\mathrm{MnO}_{2}$ 纳米线作催化 剂具有最佳的电化学性能, 并指出这与 $\alpha-\mathrm{MnO}_{2}$ 晶 体的特殊的隧道结构有关。Chen 等 ${ }^{47}$ 发现同时载上 两种金属氧化物催化剂较单一催化剂的性能更好, $\mathrm{Fe}_{2} \mathrm{O}_{3} @ \mathrm{C} @ \mathrm{MnO}_{2}$ 材料就比单一的 $\mathrm{C}$ 和 $\mathrm{Fe}_{2} \mathrm{O}_{3} @ \mathrm{C}$ 更 能明显降低 OER 和 ORR 的过电压、稳定界面阻 抗, 从而极大地提高了循环寿命。Nazar 等 ${ }^{48}$ 将合 成的具有烧绿石 $\mathrm{A}_{2} \mathrm{~B}_{2} \mathrm{O}_{7}$ 结构的介孔 $\mathrm{Pb}_{2} \mathrm{Ru}_{2} \mathrm{O}_{6.5}$ 材料 作为锂-空气电池催化剂, 发现其中的氧空位提高 了催化剂对 OER 和 ORR 催化活性, 在 $70 \mathrm{~mA} \cdot \mathrm{g}^{-1}$ 电流密度下, 最大放电容量高达 $10400 \mathrm{mAh} \cdot \mathrm{g}^{-1}$ (图6)。

此外, 在锂-空气电池中也开展了尖晶石类
$\left(\mathrm{NiCo}_{2} \mathrm{O}_{4}{ }^{49-51} 、 \mathrm{MnCo}_{2} \mathrm{O}_{4}{ }^{52} 、 \mathrm{CoFe}_{2} \mathrm{O}_{4}{ }^{53}\right.$ 和 $\left.\mathrm{CuCo}_{2} \mathrm{O}_{4}{ }^{54}\right)$ 和钙钛矿类 $\left(\mathrm{CaMnO}_{3}{ }^{55} 、 \mathrm{Sr}_{2} \mathrm{CrMoO}_{6-\delta}{ }^{56} 、 \mathrm{LaNiO}_{3}{ }^{57}\right.$ 、 $\mathrm{La}_{0.5} \mathrm{Sr}_{0.5} \mathrm{CoO}_{2.91}{ }^{58}$ 及 $\mathrm{La}_{0.75} \mathrm{Sr}_{0.25} \mathrm{MnO}_{3}{ }^{59}$ ) 等混合过渡金 属氧化物等催化剂的相关研究, 也都显示出了较 高的催化活性。

虽然过渡金属氧化物作为催化剂具有较好的 ORR 和 OER 催化活性, 并获得了较高的放电比容 量和容量保持率, 但是循环寿命较差, 而且在大 电流密度下极化较严重, 需要进一步优化过渡金 属氧化物的结构来提高电池的性能。

\subsection{3 过渡金属氮化物和碳化物}

金属氮化物和碳化物具有较好的化学惰性、 导电导热性以及优异的催化性能, 在锂-空气电池 中的应用也取得了一些重要进展。

Zhou 等 ${ }^{60}$ 利用模板法在商业碳 XC-72(VC)上负 载的 TiN 纳米颗粒能明显提高锂-空气电池的放电 比容量, 降低充放电过电势, 在 $500 \mathrm{~mA} \cdot \mathrm{g}^{-1}$ 的电 流密度下比容量仍达到 $6407 \mathrm{mAh} \cdot \mathrm{g}^{-1}$ 。 Park 等 ${ }^{61}$ 通 过模板法合成的介孔 TiN 催化剂, 廖小珍等 ${ }^{2}$ 合成 的 Co-N/C 催化剂, Cui 等 ${ }^{63-65}$ 合成的 MoN/N-C 纳米 球、介孔 $\mathrm{Co}_{3} \mathrm{Mo}_{3} \mathrm{~N}$ 、石墨烯负载 $\mathrm{MoN}$ 等氮化物, 也都表现出较好的 ORR 催化活性和循环稳定性。 Sun 等 ${ }^{6}$ 制备的 $\mathrm{Mo}_{2} \mathrm{C} / \mathrm{CNT}$ 纳米颗粒催化剂在循环 过程中会在 $\mathrm{Mo}_{2} \mathrm{C}$ 表面形成的一层非晶的 $\mathrm{MoO}_{3}$ 纳 米颗粒 $\left(\mathrm{MoO}_{3} @ \mathrm{Mo}_{2} \mathrm{C}\right)$, 而 DFT 计算表明这种非晶 的 $\mathrm{MoO}_{3}$ 纳米颗粒能够显著降低 $\mathrm{O}_{2}$ 在 $\mathrm{Mo}_{2} \mathrm{C}$ 表面的 吸附能, 从而有利于 ORR 和 OER 反应的进行, 在 用作锂-空气电池的催化剂时, 充电电压仅有 3.25 $\mathrm{V}$, 充放电效率高达 $88 \%$ (见图 7(a)), 而且循环 100 次后, 充电电压依然低于 $3.40 \mathrm{~V}$ (见图7(b)), 优于 


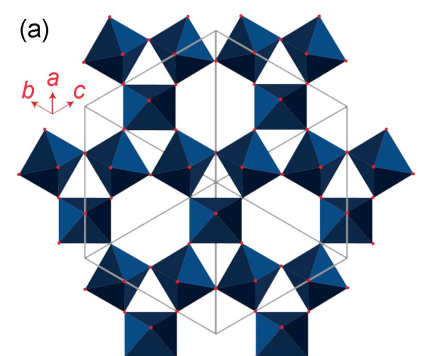

electron pathway (b)

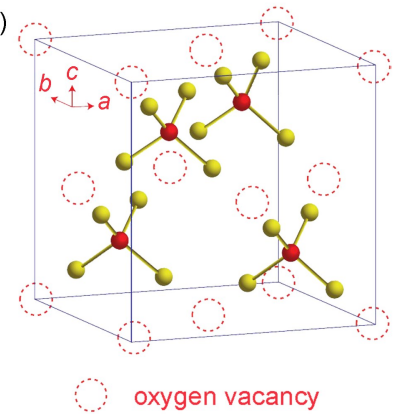

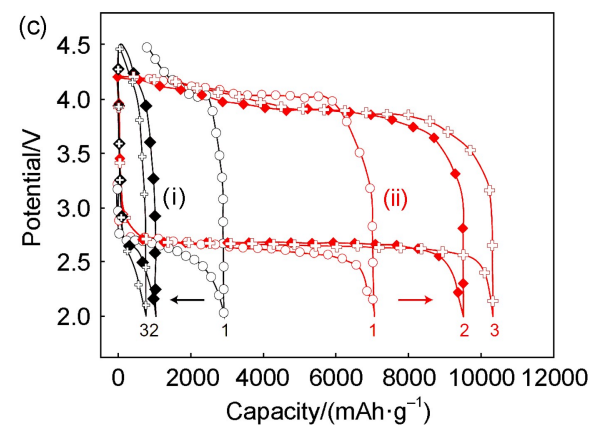

图 6 (a) $\mathrm{Pb}_{2} \mathrm{Ru}_{2} \mathrm{O}_{6.5}$ 烧绿石中的电子导电路径; (b) $\mathrm{Pb}_{2} \mathrm{Ru}_{2} \mathrm{O}_{6.5}$ 的氧空位示意图;

(c) 介孔 $\mathrm{Pb}_{2} \mathrm{Ru}_{2} \mathrm{O}_{6.5}$ 电极和碳电极的前 3 次充放电曲线 ${ }^{48}$

Fig.6 (a) Structure of the pyrochlore $\mathrm{Pb}_{2} \mathrm{Ru}_{2} \mathrm{O}_{6.5}$ showing electron conduction paths; (b) schematic framework of oxygen vacancies in the mesoporous $\mathrm{Pb}_{2} \mathrm{Ru}_{2} \mathrm{O}_{6.5}$; (c) discharge/charge profiles of the first three cycles for carbon and $\mathrm{Pb}_{2} \mathrm{Ru}_{2} \mathrm{O}_{6.5}$ electrode $^{48}$
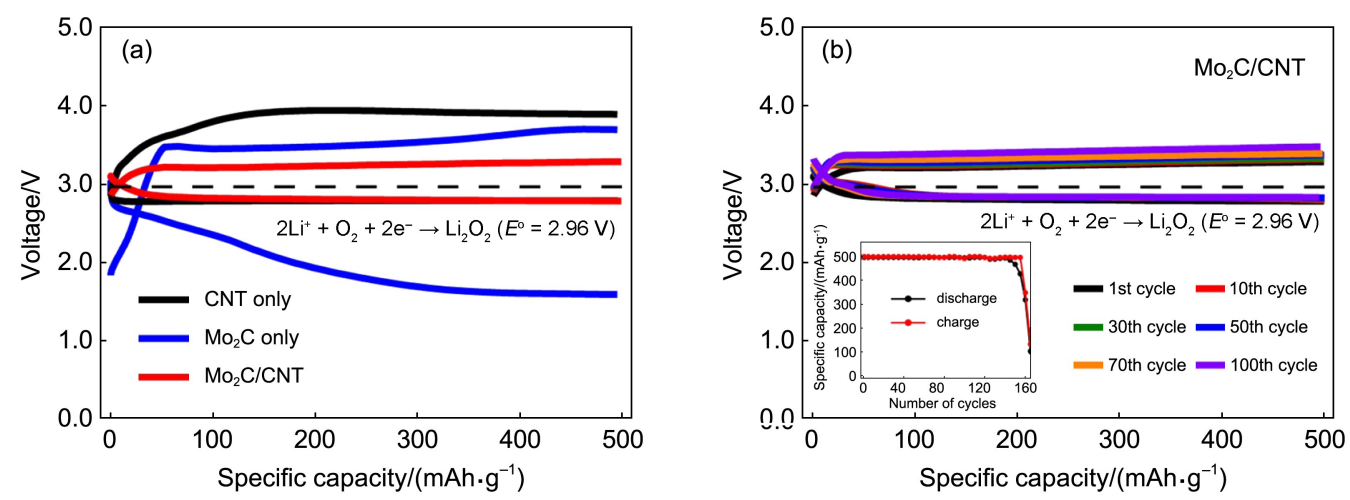

图 7 (a) CNT、 $\mathrm{Mo}_{2} \mathrm{C}$ 和 $\mathrm{Mo}_{2} \mathrm{C} / \mathrm{CNT}$ 三种锂-空气电池电极在电流密度为 $100 \mathrm{~mA} \cdot \mathrm{g}^{-1}$, 限定容量为 $500 \mathrm{mAh} \cdot \mathrm{g}^{-1}$ 时的 首圈充放电曲线; (b) $\mathrm{Mo}_{2} \mathrm{C} / \mathrm{CNT}$ 锂-空气电池电极在电流密度为 $100 \mathrm{~mA} \cdot \mathrm{g}^{-1}$, 限定容量为 $500 \mathrm{mAh} \cdot \mathrm{g}^{-1}$ 时的循环性能曲线 ${ }^{66}$ Fig.7 (a) First discharge/charge profiles of the $\mathrm{Li}-\mathrm{O}_{2}$ with $\mathrm{CNT}, \mathrm{Mo}_{2} \mathrm{C}$, and $\mathrm{Mo}_{2} \mathrm{C} / \mathrm{CNT}$ electrodes at a discharge capacity of $500 \mathrm{mAh} \cdot \mathrm{g}^{-1}$ and a current density of $100 \mathrm{~mA} \cdot \mathrm{g}^{-1}$; (b) cycling performance of $\mathrm{Li}-\mathrm{O}_{2}$ with $\mathrm{Mo}_{2} \mathrm{C} / \mathrm{CNT}$ electrodes at a discharge capacity of $500 \mathrm{mAh} \cdot \mathrm{g}^{-1}$ and a current density of $100 \mathrm{~mA} \cdot \mathrm{g}^{-1}$ 66

很多贵金属催化剂的性能。Bruce 等 ${ }^{35}$ 也发现 TiC 在用作锂-空气电池正极材料时, 表面也会形成 $\mathrm{TiO}_{2}$ 纳米颗粒 $\left(\mathrm{TiO}_{2} @ \mathrm{TiC}\right)$, 而这种 $\mathrm{TiO}_{2}$ 纳米颗粒也 有利于降低充放电过电压, 提高循环效率。

上述研究表明, 金属碳化物和氮化物具有明 显的双催化功能, 性能甚至优于很多贵金属催化 剂, 但是由于金属与氮元素或碳元素形成共价键 比较困难, 合成过程都需要高温烧结, 催化剂的 尺寸难以有效地控制。因此, 寻找合适的合成方 法以及合理的控制其颗粒大小还需要大量的研究 工作。

\subsection{4 氧化-还原电对}

氧化-还原电对 $\left(\mathrm{M}^{\mathrm{rdd}} / \mathrm{M}^{\mathrm{ox}}\right)$ 也可视为一种可溶性 的催化剂: 在充电过程中, 空气电极上首先发生 的反应是 $\mathrm{M}^{\mathrm{rd}}$ 失去电子被氧化生成 $\mathrm{M}^{\mathrm{ox}}$, 然后 $\mathrm{M}^{\mathrm{ox}}$ 再 氧化 $\mathrm{Li}_{2} \mathrm{O}_{2}$, 促进 $\mathrm{Li}_{2} \mathrm{O}_{2}$ 的分解, 自身则被还原重新
生成 $\mathrm{M}^{\mathrm{red}}$ 67。由于整个过程降低了电极的反应活化 能, 所以有效地降低了充放电过电势, 减少了电 池极化。

Bruce 等 ${ }^{68}$ 采用循环伏安扫描 $(\mathrm{CVs})$ 和微分电化 学质谱分析(DEMS)对四硫富瓦烯 $\left(\mathrm{TTF} / \mathrm{TTF}^{+}\right)$, 二 茂铁 $\left(\mathrm{FC} / \mathrm{FC}^{+}\right)$及 $N, N, N^{\prime}, N^{\prime}$-四甲基对苯二胺 $(\mathrm{TMPD} /$ $\left.\mathrm{TMPD}^{+}\right)$三种氧化-还原电对进行了比较研究, 发现 $\mathrm{TTF}^{+} 、 \mathrm{FC}^{+}$和 $\mathrm{TMPD}^{+}$都能促进 $\mathrm{Li}_{2} \mathrm{O}_{2}$ 的氧化分解, 但 以 $\mathrm{TTF} / \mathrm{TTF}^{+}$的可逆性最好。在 $1 \mathrm{~mol} \cdot \mathrm{L}^{-1}$ 的 $\mathrm{LiClO}_{4} /$ DMSO 电解液中加入少量的 TTF, 在电流密度为 1 $\mathrm{mA} \cdot \mathrm{cm}^{-2}$, 限定容量为 $300 \mathrm{mAh} \cdot \mathrm{g}^{-1}$ 的条件下, 循 环超过 100 次后充电电压依然小于 $3.6 \mathrm{~V}$, 显示了 极好的循环稳定性。而且傅里叶变换红外(FTIR)测 试和表面增强拉曼光谱(SERS)显示, 放电产物主 要是 $\mathrm{Li}_{2} \mathrm{O}_{2}$, 微量生成的 $\mathrm{Li}_{2} \mathrm{CO}_{3}$ 在充电过程中能完 全分解(见图 8)。 $\mathrm{Lim}$ 等 ${ }^{69}$ 研究表明, 向 $1 \mathrm{~mol} \cdot \mathrm{L}^{-1}$ 

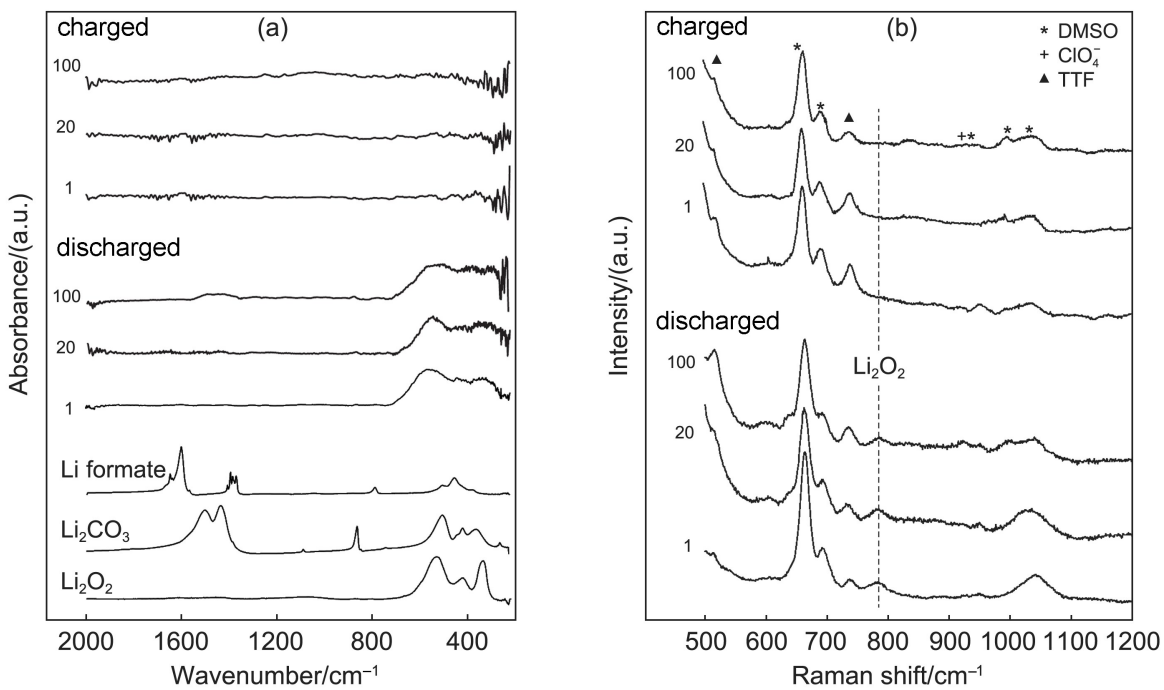

图 $8 \mathrm{NPG}$ 电极在含有 $0.01 \mathrm{~mol} \cdot \mathrm{L}^{-1} \mathrm{TTF}$ 的 $1 \mathrm{~mol} \cdot \mathrm{L}^{-1} \mathrm{LiClO}_{4} / \mathrm{DMSO}$ 电解液中循环 $1 、 20$ 和 100 次后的 FTIR (a)和 SERS (b) 光谱 ${ }^{8}$

Fig.8 Fourier transform infrared (FTIR) (a) and surface enhanced Raman scattering (SERS) (b) spectra of a NPG cathode acquired on 1, 20, and 100 cycles for $1 \mathrm{~mol} \cdot \mathrm{L}^{-1} \mathrm{LiClO}_{4} / \mathrm{DMSO}$ electrolyte containing $0.01 \mathrm{~mol} \cdot \mathrm{L}^{-1} \mathrm{TTF}^{68}$ NPG: nanoporous gold; DMSO: dimethylsulfoxide; TTF: tetrathiafulvalene

的 LiTFSI/TEGDME 电解液中加入 $0.05 \mathrm{~mol} \cdot \mathrm{L}^{-1}$ 的 $\mathrm{LiI}$, 就能在电流密度为 $2000 \mathrm{~mA} \cdot \mathrm{g}^{-1}$ 、限定容量为 $1000 \mathrm{mAh} \cdot \mathrm{g}^{-1}$ 的充放电测试条件下, 循环高达 900 次以上, 极大地改善了电池的循环性能。这是因 为在充电过程中 $\mathrm{I}^{-}$先被氧化成 $\mathrm{I}_{2}$ 或 $\mathrm{I}_{3}^{-}, \mathrm{I}_{2}$ 或 $\mathrm{I}_{3}^{-}$再氧化 分解 $\mathrm{Li}_{2} \mathrm{O}_{2}$ 。

此外, 科研人员还开展了酞菁钴 $(\mathrm{CoPc})^{70}$ 、酞 菁铁 $(\mathrm{FePc})^{71} ， 4$-氧-2,2,6,6-四甲基哌啶-1-氧自由基 $\left(\mathrm{TEMPO} / \mathrm{TEMPO}^{+}\right)^{72}$ 和三 [4- (二乙胺基) 苯基]胺 $\left(\mathrm{TDPA} / \mathrm{TDPA}^{+} / \mathrm{TDPA}^{2+}\right)^{73}$ 等多种氧化-还原电对在锂空气电池的应用研究, 发现这些可溶性的催化剂 的应用都能够降低 OER 和 ORR 的过电压, 极大地 改善电池的循环寿命。但是, 研究也发现, 可溶 性催化剂存在向锂负极扩散的问题, 并对锂负极 造成一定的影响, 同时可溶性催化剂降低充放电 过电压的机理依然需要更深入的研究。

催化剂是提高锂-空气电池性能非常关键的一 个因素, 需要科研工作者不断地开发更加高效稳 定、价格低廉的催化材料。为了更加清楚碳材料 以及各种不同类型催化剂的性能，表 1 列出了目前 研究比较普遍和比较常用的催化材料的研究结果。

\section{4 电解液}

电解液作为锂-空气电池中锂离子和氧气的传 输介质, 一般是由高纯度有机溶剂和锂盐组成。
在严苛的电化学环境下, 电解液的电化学稳定性 及热力学性质对于实现锂-空气电池的优异性能非 常重要。目前电解液的研究主要有: 碳酸酯类电 解液、醚类电解液、砜类电解液和有机胺类电解 液等。

\section{1 碳酸酯类电解液}

由于有机碳酸酯类电解液能够承受较高的充 电电压, 因此在锂-空气电池早期研究中大多采用 碳酸酯类电解液。但是 Bruce 等 ${ }^{74}$ 通过 NMR、FTIR 和 $\mathrm{MS}$ 等测试手段发现 $\mathrm{LiPF}_{6} / \mathrm{PC}$ 电解液的放电产物中 含有 $\mathrm{C}_{3} \mathrm{H}_{6}-\left(\mathrm{OCO}_{2} \mathrm{Li}\right)_{2} 、 \mathrm{Li}_{2} \mathrm{CO}_{3} 、 \mathrm{HCO}_{2} \mathrm{Li} 、 \mathrm{CH}_{3} \mathrm{CO}_{2} \mathrm{Li}$ 、 $\mathrm{CO}_{2}$ 和 $\mathrm{H}_{2} \mathrm{O}$ 等多种成分, 并认为这些副产物是由于 ORR 中间产物 $\mathrm{O}_{2}^{-}$对 PC 攻击造成的。 McCloskey 等 ${ }^{75}$ 借助原位 DEMS 也发现 EC/DMC 和 PC/DME 电 解液在充放电过程中会生成大量 $\mathrm{CO}_{2}$, 而同位素标 记显示是大部分 $\mathrm{CO}_{2}$ 来源于电解液的分解。因此, 碳酸酯类溶剂现在已基本不再用作锂-空气电池电 解液。

\section{2 醚类电解液}

醚类溶剂的氧化电压一般可以达到 $4.5 \mathrm{~V}$ 以 上, 而且与金属锂的相容性较好, 能够在很大程 度上承受 $\mathrm{O}_{2}^{-}$的攻击, 因此现在大部分锂-空气电池 都采用醚类作为电解液, 其中研究的最多的是乙 二醇二甲醚(DME)和四乙二醇二甲醚(TEGDME)。

Luntz 等 ${ }^{76}$ 借助 DEMS 测试手段, 发现 DME 体 
表 1 锂-空气电池中常用催化材料对电池放电比容量的影响

Table 1 Commonly used catalyst on the specific discharge capacity of the lithium-air batteries

\begin{tabular}{|c|c|c|c|c|c|}
\hline Catalytic material & Electrode & $\frac{\text { Specific capacity }}{\left(\mathrm{mAh} \cdot \mathrm{g}^{-1}\right)}$ & Current density & $\begin{array}{c}\text { Normalized by the } \\
\text { mass of material }\end{array}$ & Reference \\
\hline \multirow[t]{5}{*}{ carbon } & CNT fibrils & 3000 & $2000 \mathrm{~mA} \cdot \mathrm{g}^{-1}$ & CNT & 22 \\
\hline & hierarchically porous graphene & 15000 & $0.1 \mathrm{~mA} \cdot \mathrm{cm}^{-2}$ & carbon & 23 \\
\hline & mesoporous carbon nanocube & 22390 & $400 \mathrm{~mA} \cdot \mathrm{g}^{-1}$ & carbon & 26 \\
\hline & bicontinuous nanoporous graphene & 10400 & $300 \mathrm{~mA} \cdot \mathrm{g}^{-1}$ & carbon & 27 \\
\hline & mesocellular carbon foam & 2500 & $0.1 \mathrm{~mA} \cdot \mathrm{cm}^{-2}$ & carbon & 29 \\
\hline \multirow[t]{6}{*}{ precious metal } & nanoporous gold & 300 & $500 \mathrm{~mA} \cdot \mathrm{g}^{-1}$ & $\mathrm{Au}$ & 34 \\
\hline & $\mathrm{PtAu} / \mathrm{C}$ & 1500 & $500 \mathrm{~mA} \cdot \mathrm{g}^{-1}$ & carbon & 36 \\
\hline & $\mathrm{CNT} @ \mathrm{RuO}_{2}$ & 4350 & $100 \mathrm{~mA} \cdot \mathrm{g}^{-1}$ & total cathode & 38 \\
\hline & Ru@porous graphene & 17710 & $200 \mathrm{~mA} \cdot \mathrm{g}^{-1}$ & graphene & 39 \\
\hline & porous AgPd-Pd composite & 2650 & $0.2 \mathrm{~mA} \cdot \mathrm{g}^{-1}$ & total cathode & 42 \\
\hline & Pd-modified hollow sphericalcarbon & 12254 & $200 \mathrm{~mA} \cdot \mathrm{g}^{-1}$ & carbon & 43 \\
\hline transition metal & carbon $/ \alpha-\mathrm{MnO}_{2}$ nanowires & 3000 & $70 \mathrm{~mA} \cdot \mathrm{g}^{-1}$ & carbon & 46 \\
\hline \multirow[t]{7}{*}{ oxide } & $\mathrm{Fe}_{2} \mathrm{O}_{3} @ \mathrm{C} @ \mathrm{MnO}_{2}$ & 10200 & $100 \mathrm{~mA} \cdot \mathrm{g}^{-1}$ & $\mathrm{Fe}_{2} \mathrm{O}_{3} @ \mathrm{C} @ \mathrm{MnO}_{2}$ & 47 \\
\hline & $\mathrm{Pb}_{2} \mathrm{Ru}_{2} \mathrm{O}_{6.5}$ & 10400 & $70 \mathrm{~mA} \cdot \mathrm{g}^{-1}$ & carbon & 48 \\
\hline & $\mathrm{MnCo}_{2} \mathrm{O}_{4}$-graphene & 3784 & $100 \mathrm{~mA} \cdot \mathrm{g}^{-1}$ & $\mathrm{MnCo}_{2} \mathrm{O}_{4}$-graphene & 52 \\
\hline & $\mathrm{CoFe}_{2} \mathrm{O}_{4} / \mathrm{rGO}$ & 12235 & $50 \mathrm{~mA} \cdot \mathrm{g}^{-1}$ & rGO & 53 \\
\hline & $\mathrm{La}_{0.5} \mathrm{Sr}_{0.5} \mathrm{CoO}_{2.91}$ porous nanowires & 11059 & $50 \mathrm{~mA} \cdot \mathrm{g}^{-1}$ & total cathode & 58 \\
\hline & porous $\mathrm{La}_{0.75} \mathrm{Sr}_{0.25} \mathrm{MnO}_{3}$ nanotubes & 11000 & $0.025 \mathrm{~mA} \cdot \mathrm{cm}^{-2}$ & carbon & 59 \\
\hline & $\mathrm{TiC}$ & 500 & $0.5 \mathrm{~mA} \cdot \mathrm{cm}^{-2}$ & $\mathrm{TiC}$ & 35 \\
\hline \multirow{4}{*}{$\begin{array}{c}\text { metal carbide/ } \\
\text { nitride }\end{array}$} & nanoparticles TiN/Vulcan XC-72 & 6407 & $500 \mathrm{~mA} \cdot \mathrm{g}^{-1}$ & carbon & 60 \\
\hline & bimodal mesoporous TiN/carbon & 19100 & $100 \mathrm{~mA} \cdot \mathrm{g}^{-1}$ & carbon & 61 \\
\hline & $\mathrm{MoN} / \mathrm{N}-\mathrm{C}$ & 1400 & $0.1 \mathrm{~mA} \cdot \mathrm{cm}^{-2}$ & total cathode & 63 \\
\hline & $\mathrm{Mo}_{2} \mathrm{C} / \mathrm{CNT}$ & 10000 & $100 \mathrm{~mA} \cdot \mathrm{g}^{-1}$ & total cathode & 66 \\
\hline
\end{tabular}

系在充电过程中的主要产物是 $\mathrm{O}_{2}$, 而 PC/DME 体 系的主要产物是 $\mathrm{CO}_{2}$, 认为醚类电解液比碳酸酯类 更加稳定，但同时也发现催化剂Pt 会催化电解液 $\mathrm{DME}$ 的分解释放 $\mathrm{CO}_{2}$ (见图 9)。

TEGDME 由于挥发性小, 与金属锂的相容性 好, 是目前锂-空气电池研究中普遍采用的电解 液。但随着研究的深入, Bruce 等 ${ }^{77}$ 通过 FTIR、 NMR、Raman 和 DEMS 等测试手段在醚类电解液 的放电产物中也检测到 $\mathrm{Li}_{2} \mathrm{CO}_{3} 、 \mathrm{HCO}_{2} \mathrm{Li}$ 、 $\mathrm{CH}_{3} \mathrm{CO}_{2} \mathrm{Li} 、 \mathrm{H}_{2} \mathrm{O}$ 和 $\mathrm{CO}_{2}$ 等产物, 证实了醚类在充放 电过程中也会发生分解。

\section{3 砜类电解液}

砜类溶剂(主要是指二甲基亚砜(DMSO)和环丁 砜(TMS)) 的电化学稳定性都较高, 而且承受 $\mathrm{O}_{2}^{-}$攻 击的能力较强, 以砜类(DMSO)为电解液的电池都 能获得较高的容量及良好的循环性能 ${ }^{78,79}$ 。

但 Sharon 等 ${ }^{80}$ 以 $1 \mathrm{~mol} \cdot \mathrm{L}^{-1}$ 的 $\mathrm{LiPF}_{6} / \mathrm{DMSO}$ 为电 解液, 研究发现以碳电极作空气电极时, 放电产 物中检测到少量的 $\mathrm{LiOH} 、 \mathrm{DMSO}_{2} 、 \mathrm{Li}_{2} \mathrm{SO}_{3}$ 和 $\mathrm{Li}_{2} \mathrm{SO}_{4}$ 等副产物, 认为 $\mathrm{DMSO}$ 在充电过程中电解液 发生了分解，并提出了可能的分解机理(见图 10)。
Zhang 等 ${ }^{81}$ 发现 TMS 的氧化分解电压大于 5.6 $\mathrm{V}$, 比 DMSO 具有更好的稳定性, 在锂-空气电池 中的应用也获得了较好的效果。但 TMS 较高的凝 固点 $\left(27.4^{\circ} \mathrm{C}\right)$ 及较大的粘度限制了其在锂-空气电 池中的应用。

\section{4 胺类电解液}

由于胺类化合物(主要是二甲基甲酰胺(DMF) 和二甲基乙酰胺(DMA))在充放电过程中会生成大 量的副产物 ${ }^{82}$, 而且金属锂负极会与胺类有机化合 物反应, 所以胺类电解液在锂-空气电池中的应用 研究较少。但 Addison 等 ${ }^{83}$ 以 $1 \mathrm{~mol} \cdot \mathrm{L}^{-1}$ 的 $\mathrm{LiNO}_{3} /$ DMA 为电解液, 利用 $\mathrm{NO}_{3}^{-}$的强氧化性, 在锂负极 表面被还原生成稳定的致密 SEI 膜来阻止金属锂片 与 DMA 反应, 最终电池在电流密度 $0.1 \mathrm{~mA} \cdot \mathrm{cm}^{-2}$ 的条件下也能够稳定循环 80 次以上, 并且放电产 物主要是 $\mathrm{Li}_{2} \mathrm{O}_{2}$ 。

此外, 离子液体由于低挥发性、高稳定性、 高导电性以及较宽的电化学窗口等特性, 因此与 传统的有机电解液相比, 更能显著的降低充放电 过电压, 减少副反应的发生, 提高循环效率 ${ }^{84-88}$, 但离子液体也存在粘度大、溶氧量低、传质阻力 

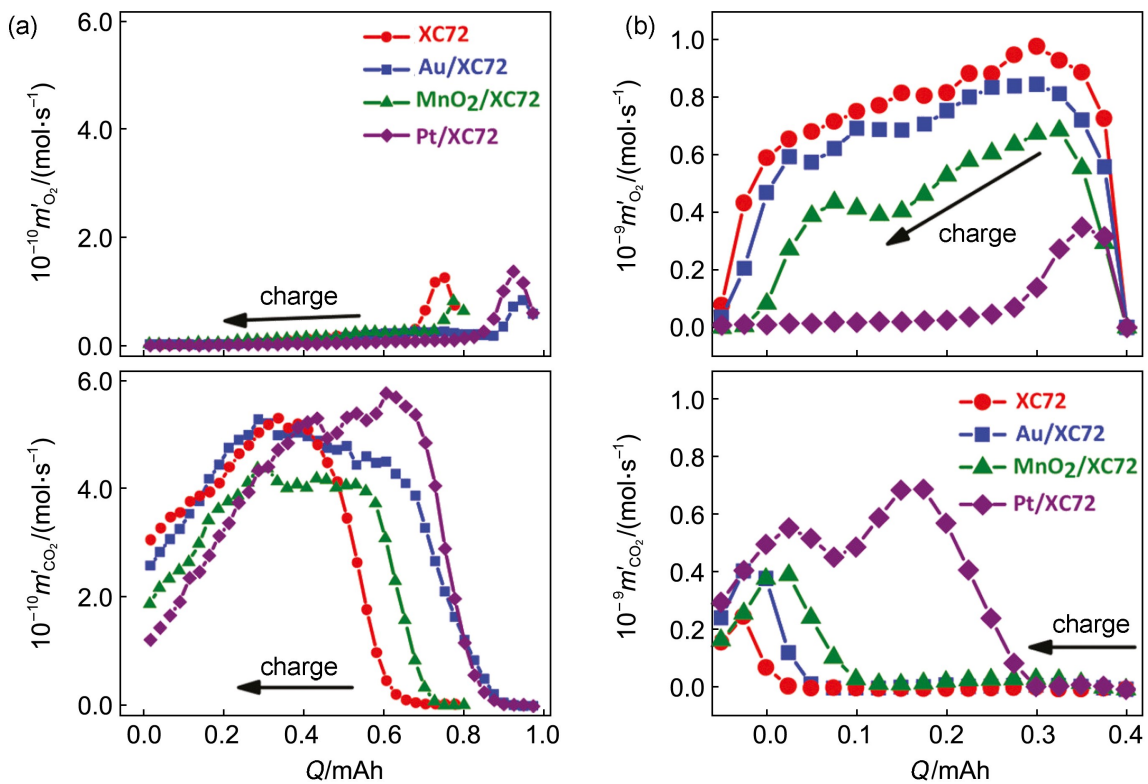

图9 不同电解液体系充电过程中 $\mathrm{O}_{2}$ 和 $\mathrm{CO}_{2}$ 气体与充电容量之间的关系 ${ }^{76}$

Fig.9 Relation between $\mathrm{O}_{2}$ and $\mathrm{CO}_{2}$ evolution and charge capacity during charging of cells ${ }^{76}$ (a) $1: 1(V: V)$ PC/DME-based, DME-based (b); PC: propylene carbonate

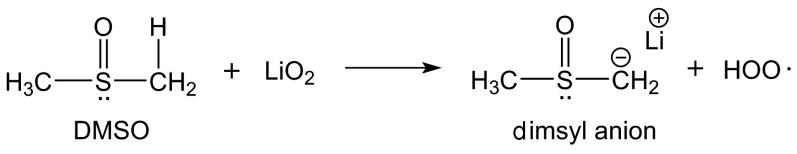

$\mathrm{HOO} \cdot \stackrel{\mathrm{Li}+1 \mathrm{e}^{-}}{\longrightarrow} \mathrm{HOO} \stackrel{\ominus}{\mathrm{Li}}$
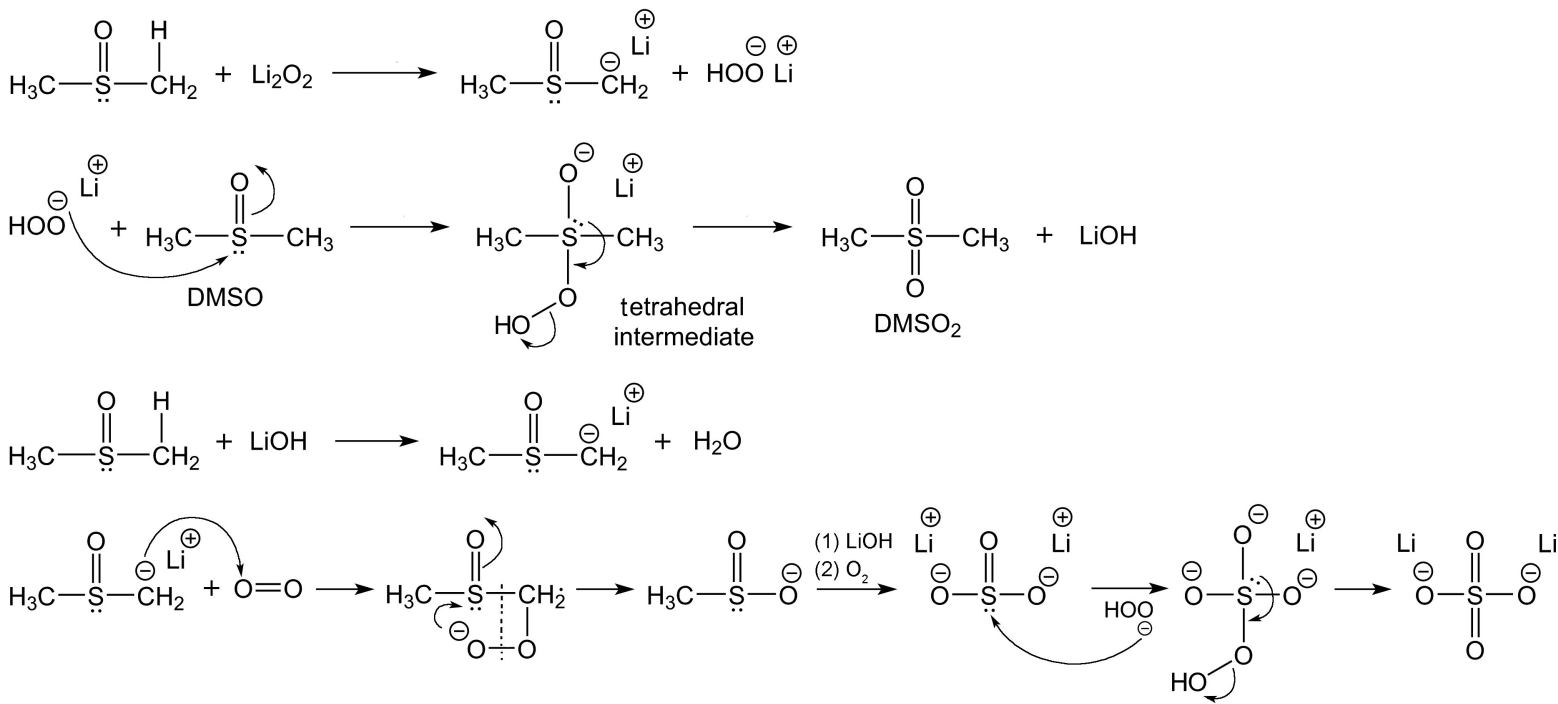

图 10 锂-空气电池中 DMSO 的分解机理 ${ }^{80}$

Fig.10 Decomposition mechanism of DMSO in Li-air batteries ${ }^{80}$

大及价格贵等缺点，限制了它的大规模的应用。

\section{5 锂负极}

常见的锂负极枝晶问题和循环寿命短问题在
锂-空气电池中依然存在，但在科研人员的不解努 力下，锂负极的应用也取得了显著的进展。

Zhang 等 ${ }^{89}$ 通过电化学的方法在锂䇴表面原位 生成致密的 $\mathrm{LiF}$ 保护膜来抑制充放电过程中锂枝晶 

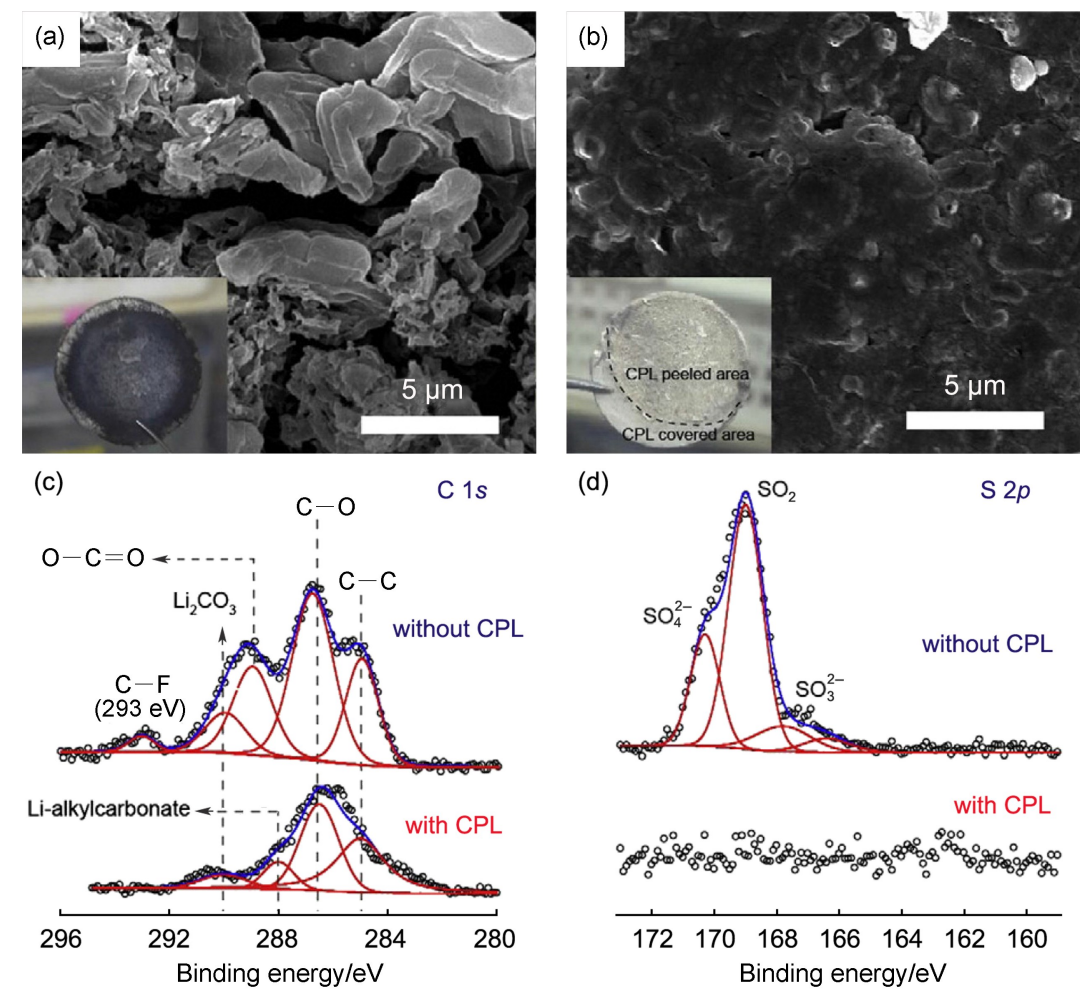

图 1180 次循环后锂负极的 $\operatorname{SEM}(a, b)$ 和 XPS $(c, d)$ 图

Fig.11 SEM images (a, b) and XPS spectra (c, d) of the Li anodes after 80 cycles $^{91}$ (a) without CPL (composite protective layer), (b) with CPL; (c) C $1 s$ and (d) S $2 p$ XPS spectra

的生长, 仅以 Super P 为空气电极, 在电流密度 $300 \mathrm{~mA} \cdot \mathrm{g}^{-1}$ 、限定容量 $1000 \mathrm{mAh} \cdot \mathrm{g}^{-1}$ 的充放电测试 条件下，具有 $\mathrm{LiF}$ 保护膜的锂负极循环超过 100 次, 是纯锂负极的 3 倍左右。而通过在锂管表面涂 上一层聚偏氟乙烯-六氟丙烯(PVDF-HFP) 保护 膜 ${ }^{90}$, 或者在锂管表面涂一层基于三氧化二铝 $\left(\mathrm{Al}_{2} \mathrm{O}_{3}\right)$ 和 PVDF-HFP 的复合保护膜(CPL) $)^{91}$, 也可以 明显抑制锂枝晶的生长, 改善电池的循环性能(见 图 11)。研究发现, 有 CPL复合保护膜的锂负极使 电池的循环性能提高 3 倍左右, 循环后 SEM 测试 显示无 CPL 保护的锂负极表面有锂枝晶生成, 而 且 XPS 也显示有 $\mathrm{Li}_{2} \mathrm{CO}_{3} 、 \mathrm{SO}_{4}^{2-}$ 和 $\mathrm{SO}_{3}^{2-}$ 等电解液分解 产物生成; 而 CPL 保护的锂负极表面比较光洁, 无明显锂枝晶生成, XPS 显示只有少量的 $\mathrm{Li}_{2} \mathrm{CO}_{3}$ 生 成, 说明 CPL复合保护膜能够有效地减少锂负极 与电解液副反应, 抑制锂枝晶的生长。

Shui 等 ${ }^{2}$ 通过同步辐射 X 射线衍射和微断层扫 描技术对锂空气电池中充放电循环后锂负极表面 的产物和微区形貌进行分析, 测试发现充放电过 程中锂䈃表面的金属锂逐渐转变为 $\mathrm{LiOH}$, 并且随 着循环次数的增加, $\mathrm{LiOH}$ 的厚度逐渐增加, 并指
出 $\mathrm{LiOH}$ 的形成是由于金属锂与电解液分解产生的 水反应形成, 因此开发更加稳定的电解液是保护 锂负极的关键问题。Hassoun 等 ${ }^{93}$ 首次将锂硅合金 $(\mathrm{Li} x \mathrm{Si})$ 作为锂空气电池的负极, 得到了可循环的 $\mathrm{Li}_{x} \mathrm{Si}-\mathrm{O}_{2}$ 电池。该电池的放电电压为 $2.4 \mathrm{~V}$ 左右, 循 环超过 15 次, 估算能量密度为 $980 \mathrm{Wh} \cdot \mathrm{kg}^{-1}$, 依然 高于商业锂离子电池。

\section{6 结论与展望}

近几年来, 在锂-空气电池的反应机理、空气 电极及电解液的开发等各方面都取得了重要进 展, 但依然存在很多问题: 首先, 充放电反应机 理还存在很大争议, 需要借助更精密的测试设备 和方法来进一步厘清; 其次, 空气电极的极化问 题还没得到根本解决, 还需设计并制备具有更加 合适比表面积、孔径和孔容的电极, 开发更高效 的双效催化剂; 再次, 电解液的分解问题仍然存 在, 需要继续开发具有电压窗口宽、电化学稳 定、高容氧量、低粘度及低挥发性特点的, 并与 正负极匹配性良好的电解液; 最后, 锂负极的保 护也是需要亟待解决的一个重要问题, 一方面需 
要研究锂空气电池中锂枝晶的形成机理, 以寻找 有效的方法抑制锂枝晶的生长; 另一方面需要研 究开发锂负极的替代材料, 降低锂负极的反应活 性，有效避免锂枝晶的形成。短期目标是要研究 在负极表面如何生成或涂覆高效保护层，而长期 目标则是开发出具有更高离子导电性的固态电解 质，彻底杜绝枝晶问题。

\section{References}

(1) Littauer, E. L.; Tsai, K. C. J. Electrochem. Soc. 1976, 123, 771. doi: $10.1149 / 1.2132931$

(2) Abraham, K. M.; Jiang, Z. J. Electrochem. Soc. 1996, 143, 1. doi: $10.1149 / 1.1836378$

(3) Ogasawara, T.; Debart, A.; Holzapfel, M.; Novak, P.; Bruce, P. G. J. Am. Chem. Soc. 2006, 128, 1390. doi: 10.1021/ja056811q

(4) Wang, Y. G.; Zhou, H. S. J. Power Sources 2010, 195, 358. doi: 10.1016/j.jpowsour.2009.06.109

(5) Kumar, B.; Kumar, J.; Leese, R.; Fellner, J. P.; Rodrigues, S. J.; Abraham, K. M. J. Electrochem. Soc. 2010, 157, A50. doi: $10.1149 / 1.3256129$

(6) Ren, X. M.; Zhang, S. S.; Tran, D. T.; Read, J. J. Mater. Chem. 2011, 21, 10118. doi: 10.1039/C0JM04170J

(7) McCloskey, B. D.; Scheffler, R.; Speidel, A.; Girishkumar, G.; Luntz, A. C. J. Phys. Chem. C 2012, 116, 23897. doi: 10.1021/ jp306680f

(8) Laoire, C. O.; Mukerjee, S.; Abraham, K. M.; Plichta, E. J.; Hendrickson, M. A. J. Phys. Chem. C 2009, 113, 20127. doi: $10.1021 / \mathrm{jp} 908090 \mathrm{~s}$

(9) Laoire, C. O.; Mukerjee, S.; Abraham, K. M.; Plichta, E. J.; Hendrickson, M. A. J. Phys. Chem. C 2010, 114, 9178. doi: $10.1021 /$ jp $102019 y$

(10) Peng, Z. Q.; Freunberger, S. A.; Hardwick, L. J.; Chen, Y. H.; Giordani, V.; Barde, F.; Novak, P.; Graham, D.; Tarascon, J. M.; Bruce, P. G. Angew. Chem. Int. Edit. 2011, 50, 6351. doi: 10.1002/anie.201100879

(11) Hummelshoj, J. S.; Luntz, A. C.; Norskov, J. K. J. Chem. Phys. 2013, 138, 034703. doi: 10.1063/1.4773242

(12) Zhai, D. Y.; Wang, H. H.; Yang, J. B.; Lau, K. C.; Li, K. X.; Amine, K.; Curtiss, L. A. J. Am. Chem. Soc. 2013, 135, 15364. doi: $10.1021 / \mathrm{ja} 403199 \mathrm{~d}$

(13) Lu, J.; Lee, Y. J.; Luo, X. Y.; Lau, K. C.; Asadi, M.; Wang, H. H.; Brombosz, S.; Wen, J. G.; Zhai, D. Y.; Chen, Z. H.; Miller, D. J.; Jeong, Y. S.; Park, J. B.; Fang, Z. Z.; Kumar, B.; SalehiKhojin, A.; Sun, Y. K.; Curtiss, L. A.; Amine, K. Nature 2016, 529, 377. doi: 10.1038/nature16484

(14) Aetukuri1, N. B.; McCloskey, B. D.; García1, J. M.; Krupp, L. E.; Viswanathan, V.; Luntz., A. C. Nat. Chem. 2015, 7, 50. doi: $10.1038 /$ nchem. 2132

(15) Liu, T.; Leskes, M.; Yu, W. J.; Moore, A. J.; Zhou, L. N.; Bayley, P. M.; Kim, G.; Grey, C. P. Science 2015, 350, 530. doi: $10.1126 /$ science.aac 7730

(16) Girishkumar, G.; McCloskey, B.; Luntz, A. C.; Swanson, S.; Wilcke, W. J. Phys. Chem. Lett. 2010, 1, 2193. doi: 10.1021/ jz1005384

(17) Xiao, J.; Wang, D. H.; Xu, W.; Wang, D. Y.; Williford, R. E.; Liu, J.; Zhang, J. G. J. Electrochem. Soc. 2010, 157, A487. doi: $10.1149 / 1.3314375$

(18) Tran, C.; Yang, X. Q.; Qu, D. Y. J. Power Sources 2010, 195, 2057. doi: 10.1016/j.jpowsour.2009.10.012

(19) Hayashi, M.; Minowa, H.; Takahashi, M.; Shodai, T. Electrochemistry 2010, 78, 325.

(20) Mirzaeian, M.; Hall, P. J. Electrochim. Acta 2009, 54, 7444. doi: 10.1016/j.electacta.2009.07.079

(21) Yang, X. H.; He, P.; Xia, Y. Y. Electrochem. Commun. 2009, 11, 1127. doi: 10.1016/j.elecom.2009.03.029

(22) Lim, H. D.; Park, K. Y.; Song, H.; Jang, E. Y.; Gwon, H.; Kim, J.; Kim, Y. H.; Lima, M. D.; Robles, R. O.; Lepro, X.; Baughman, R. H.; Kang, K. Adv. Mater. 2013, 25, 1348 doi: 10.1039/c3ee41910j

(23) Xiao, J.; Mei, D. H.; Li, X. L.; Xu, W.; Wang, D. Y.; Graff, G. L.; Bennett, W. D.; Nie, Z. M.; Saraf, L. V.; Aksay, I. A.; Liu, J.; Zhang, J. G. Nano Lett. 2011, 11, 5071. doi: 10.1021/n1203332e

(24) Xia, G. F.; Shen, S. Y.; Zhu, F. J.; Xie, J. Y.; Hu, Y. F.; Zhu, K.; Zhang, J. L. Electrochem. Commun. 2015, 60, 26. doi: 10.1016/j. elecom.2015.07.011

(25) Tong, S. F.; Zheng, M. B.; Lu, Y.; Lin, Z. X.; Zhang, X. P.; He, P.; Zhou, H. S. Chem. Commun. 2015, 51, 7302. doi: 10.1039/ $\mathrm{c} 5 \mathrm{cc} 01114 \mathrm{k}$

(26) Sun, B.; Chen, S. Q.; Liu, H.; Wang, G. X. Adv. Funct. Mater. 2015, 25, 4436. doi: 10.1002/adfm.201500863

(27) Han, J. H.; Guo, X. W.; Ito, Y.; Liu, P.; Hojo, D.; Aida, T.; Hirata, A.; Fujita, T.; Adschiri, T.; Zhou, H. S.; Chen, M. W. Adv. Energy Mater. 2016, 6. doi: 10.1002/aenm.201501870

(28) Li, Q.; Xu, P.; Gao, W.; Ma, S. G.; Zhang, G. Q.; Cao, R. G.; Cho, J.; Wang, H. L.; Wu, G. Adv. Mater. 2014, 26, 1378. doi: 10.1002/adma.201304218

(29) Yang, X. H.; He, P.; Xia, Y. Y. Electrochem. Commun. 2009, 11, 1127. doi: 10.1016/j.elecom.2009.03.029

(30) Gowda, S. R.; Brunet, A.; Wallraff, G. M.; McCloskey, B. D. J. Phys. Chem. Lett. 2013, 4, 276. doi: 10.1021/jz301902h

(31) McCloskey, B. D.; Speidel, A.; Scheffler, R.; Miller, D. C.; Viswanathan, V.; Hummelshoj, J. S.; Norskov, J. K.; Luntz, A. C. J. Phys. Chem. Lett. 2012, 3, 997. doi: 10.1021/jz300243r

(32) Liu, Q. C.; Xu, J. J.; Xu, D.; Zhang, X. B. Nat. Commun. 2015, 6, 7892. doi: $10.1038 /$ ncomms 8892

(33) Xu, S. M.; Zhu, Q. C.; Du, F. H.; Li, X. H.; Wei, X.; Wang, K. X.; Chen, J. S. Dalton Trans. 2015, 44, 8678. doi: 10.1039/ C5DT00498E

(34) Peng, Z. Q.; Freunberger, S. A.; Chen, Y. H.; Bruce, P. G. Science 2012, 337, 563. doi: 10.1126/science. 1223985

(35) Thotiyl, M. M. O.; Freunberger, S. A.; Peng, Z. Q.; Chen, Y. H.; 
Liu, Z.; Bruce, P. G. Nat. Mater. 2013, 12, 1050. doi: 10.1038/ nmat 3737

(36) Lu, Y. C.; Xu, Z. C.; Gasteiger, H. A.; Chen, S.; HamadSchifferli, K.; Shao-Horn, Y. J. Am. Chem. Soc. 2010, 132, 12170. doi: $10.1021 /$ ja1036572

(37) Lu, Y. C.; Gasteiger, H. A.; Shao-Horn, Y. J. Am. Chem. Soc. 2011, 133, 19048. doi: 10.1021/ja208608s

(38) Jian, Z. L.; Liu, P.; Li, F. J.; He, P.; Guo, X. W.; Chen, M. W.; Zhou, H. S. Angew. Chem. Int. Edit. 2014, 53, 442. doi: 10.1002/ anie. 201307976

(39) Sun, B.; Huang, X. D.; Chen, S. Q.; Munroe, P.; Wang, G. X. Nano Lett. 2014, 14, 3145. doi: 10.1021/n1500397y

(40) Zhou, W.; Cheng, Y.; Yang, X. F.; Wu, B. S.; Nie, H. J.; Zhang, H. Z.; Zhang, H. M. J. Mater. Chem. A 2015, 3, 14556. doi: $10.1039 / \mathrm{c} 5$ ta03482e

(41) Kim, S. T.; Choi, N. S.; Park, S.; Cho, J. Adv. Energy Mater. 2015, 5. doi: 10.1002/aenm.201401030

(42) Luo, W. B.; Gao, X. W.; Chou, S. L.; Wang, J. Z.; Liu, H. K. Adv. Mater. 2015, 27, 6862. doi: 10.1002/adma.201502262

(43) Xu, J. J.; Wang, Z. L.; Xu, D.; Zhang, L. L.; Zhang, X. B. Nat. Commun. 2013, 4, 2438. doi: 10.1038/ncomms3438

(44) Liu, Q. C.; Li, L.; Xu, J. J.; Chang, Z. W.; Xu, D.; Yin, Y. B.; Yang, X. Y.; Liu, T.; Jiang, Y. S.; Yan, J. M.; Zhang, X. B. Adv. Mater. 2015, 27, 8095. doi: 10.1002/adma.201503025

(45) Debart, A.; Bao, J.; Armstrong, G.; Bruce, P. G. J. Power Sources 2007, 174, 1177. doi: 10.1016/j.jpowsour.2007.06.180

(46) Débart, A.; Paterson, A. J.; Bao, J.; Bruce, P. G. Angew. Chem. 2008, 120, 4597. doi: 10.1002/ange.200705648

(47) Hu, X.; Cheng, F.; Zhang, N.; Han, X.; Chen, J. Small 2015, 11, 5545. doi: $10.1002 / \mathrm{smll} .201501570$

(48) Oh, S. H.; Black, R.; Pomerantseva, E.; Lee, J. H.; Nazar, L. F. Nat. Chem. 2012, 4, 1004. doi: 10.1038/NCHEM.1499

(49) Xiong, W.; Gao, Y. S.; Wu, X.; Hu, X.; Lan, D. N.; Chen, Y. Y.; Pu, X. L.; Zeng, Y.; Su, J.; Zhu, Z. H. ACS Appl. Mater. Inter. 2014, 6, 19416. doi: 10.1021/am5055228

(50) Sun, B.; Zhang, J. Q.; Munroe, P.; Ahn, H. J.; Wang, G. Electrochem. Commun. 2013, 31, 88. doi: 10.1016/j. elecom.2013.03.023

(51) Zhang, L.; Zhang, S.; Zhang, K.; Xu, G.; He, X.; Dong, S.; Liu, Z.; Huang, C.; Gu, L.; Cui, G. Chem. Commun. 2013, 49, 3540. doi: 10.1039/c3ec40393a

(52) Wang, H. L.; Yang, Y.; Liang, Y. Y.; Zheng, G. Y.; Li, Y. G.; Cui, Y.; Dai, H. J. Energ Environ. Sci. 2012, 5, 7931. doi: 10.1039/ c2ee21746e

(53) Cao, Y.; Cai, S. R.; Fan, S. C.; Hu, W. Q.; Zheng, M. S.; Dong, Q. F. Faraday Discuss. 2014, 172, 215. doi: 10.1039/c4fd00075g

(54) Liu, Y.; Cao, L. J.; Cao, C. W.; Wang, M.; Leung, K. L.; Zeng, S. S.; Hung, T. F.; Chung, C. Y.; Lu, Z. G. Chem. Commun. 2014, 50,14635 .

(55) Han, X. P.; Hu, Y. X.; Yang, J. G.; Cheng, F. Y.; Chen, J. Chem. Commun. 2014, 50, 1497. doi: 10.1039/c3cc48207c
(56) Ma, Z.; Yuan, X. X.; Li, L.; Ma, Z. F. Chem. Commun. 2014, 50, 14855. doi: 10.1039/c4cc06113f

(57) Wei, Z. H.; Zhao, T. S.; Zhu, X. B.; An, L.; Tan, P. Energy Technol. 2015, 3, 1093. doi: 10.1002/ente.201500153

(58) Zhao, Y. L.; Xu, L.; Mai, L. Q.; Han, C. H.; An, Q. Y.; Xu, X.; Liu, X.; Zhang, Q. J. Proc. Natl. Acad. Sci. U. S. A. 2012, 109, 19569. doi: 10.1073/pnas.1210315109

(59) Xu, J. J.; Xu, D.; Wang, Z. L.; Wang, H. G.; Zhang, L. L.; Zhang, X. B. Angew. Chem. Int. Edit. 2013, 52, 3887. doi: 10.1002/anie.201210057

(60) Li, F. J.; Ohnishi, R.; Yamada, Y.; Kubota, J.; Domen, K.; Yamada, A.; Zhou, H. S. Chem. Commun. 2013, 49, 1175. doi: $10.1039 / \mathrm{c} 2 \mathrm{cc} 37042 \mathrm{e}$

(61) Park, J.; Jun, Y. S.; Lee, W. R.; Gerbec, J. A.; See, K. A.; Stucky, G. D. Chem. Mater. 2013, 25, 3779. doi: 10.1021/cm401794r

(62) Yang, B. J.; Wang, H.; Li, L.; Huang, B. W.; Liao, X. Z.; He, Y. S.; Ma, Z. F. Acta Phys. -Chim. Sin. 2014, 30, 150. [阳炳检, 王 红, 李 否, 黄博文, 廖小珍, 何雨石, 马紫峰. 物理化学学报, 2014, 30, 150.] doi: 10.3866/PKU.WHXB201311142

(63) Zhang, K. J.; Zhang, L. X.; Chen, X.; He, X.; Wang, X. G.; Dong, S. M.; Gu, L.; Liu, Z. H.; Huang, C. S.; Cui, G. L. ACS Appl. Mater. Inter. 2013, 5, 3677. doi: 10.1021/am400209u

(64) Zhang, K. J.; Zhang, L. X.; Chen, X.; He, X.; Wang, X. G.; Dong, S. M.; Han, P. X.; Zhang, C. J.; Wang, S.; Gu, L.; Cui, G. L. J. Phys. Chem. C 2013, 117, 858. doi: 10.1021/jp310571y

(65) Dong, S. M.; Chen, X.; Zhang, K. J.; Gu, L.; Zhang, L. X.; Zhou, X. H.; Li, L. F.; Liu, Z. H.; Han, P. X.; Xu, H. X.; Yao, J. H.; Zhang, C. J.; Zhang, X. Y.; Shang, C. Q.; Cui, G. L.; Chen, L. Q. Chem. Commun. 2011, 47, 11291. doi: 10.1039/ c1cc14427h

(66) Kwak, W. J.; Lau, K. C.; Shin, C. D.; Amine, K.; Curtiss, L. A.; Sun, Y. K. ACS Nano 2015, 9, 4129. doi: 10.1021/ acsnano. 5 b00267

(67) Yu, M. Z.; Ren, X. D.; Ma, L.; Wu, Y. Y. Nat. Commun. 2014, 5. doi: $10.1038 /$ ncomms6111

(68) Chen, Y. H.; Freunberger, S. A.; Peng, Z. Q.; Fontaine, O.; Bruce, P. G. Nat. Chem. 2013, 5, 489. doi: 10.1038/nchem.1646

(69) Lim, H. D.; Song, H.; Kim, J.; Gwon, H.; Bae, Y.; Park, K. Y.; Hong, J.; Kim, H.; Kim, T.; Kim, Y. H.; Lepro, X.; OvalleRobles, R.; Baughman, R. H.; Kang, K. Angew. Chem. Int. Edit. 2014, 53, 3926. doi: 10.1002/anie.201400711

(70) Trahan, M. J.; Gunasekara, I.; Mukerjee, S.; Plichta, E. J.; Hendrickson, M. A.; Abraham, K. M. J. Electrochem. Soc. 2014, 161, A1706. doi: 10.1149/2.0981410jes

(71) Sun, D.; Shen, Y.; Zhang, W.; Yu, L.; Yi, Z. Q.; Yin, W.; Wang, D.; Huang, Y. H.; Wang, J.; Wang, D. L.; Goodenough, J. B. J. Am. Chem. Soc. 2014, 136, 8941. doi: 10.1021/ja501877e

(72) Bergner, B. J.; Schurmann, A.; Peppler, K.; Garsuch, A.; Janek, J. J. Am. Chem. Soc. 2014, 136, 15054. doi: 10.1021/ja508400m

(73) Kundu, D.; Black, R.; Adams, B.; Nazar, L. F. ACS Cent. Sci. 2015, 1,510 . doi: 10.1021/acscentsci.5b00267 
(74) Freunberger, S. A.; Chen, Y. H.; Peng, Z. Q.; Griffin, J. M.; Hardwick, L. J.; Barde, F.; Novak, P.; Bruce, P. G. J. Am. Chem. Soc. 2011, 133, 8040. doi: 10.1021/ja2021747

(75) McCloskey, B. D.; Bethune, D. S.; Shelby, R. M.; Girishkumar, G.; Luntz, A. C. J. Phys. Chem. Lett. 2011, 2, 1161. doi: $10.1021 / \mathrm{jz} 200352 \mathrm{v}$

(76) McCloskey, B. D.; Scheffler, R.; Speidel, A.; Bethune, D. S.; Shelby, R. M.; Luntz, A. C. J. Am. Chem. Soc. 2011, 133, 18038. doi: $10.1021 / \mathrm{ja} 207229 \mathrm{n}$

(77) Freunberger, S. A.; Chen, Y. H.; Drewett, N. E.; Hardwick, L. J.; Barde, F.; Bruce, P. G. Angew. Chem. Int. Edit. 2011, 50, 8609. doi: 10.1002/anie.201102357

(78) Takechi, K.; Higashi, S.; Mizuno, F.; Nishikoori, H.; Iba, H.; Shiga, T. ECS Electrochem. Lett. 2012, 1, A27. doi: 10.1149/ 2.010201eel

(79) Xu, D.; Wang, Z. L.; Xu, J. J.; Zhang, L. L.; Zhang, X. B. Chem. Commun. 2012, 48, 6948. doi: 10.1039/c2cc32844e

(80) Sharon, D.; Afri, M.; Noked, M.; Garsuch, A.; Frimer, A. A.; Aurbach, D. J. Phys. Chem. Lett. 2013, 4, 3115. doi: 10.1021/ jz4017188

(81) Xu, D.; Wang, Z. L.; Xu, J. J.; Zhang, L. L.; Wang, L. M.; Zhang, X. B. Chem. Commun. 2012, 48, 11674. doi: 10.1039/ c2cc36815c

(82) Chen, Y.; Freunberger, S. A.; Peng, Z.; Barde, F.; Bruce, P. G. J. Am. Chem. Soc. 2012, 134, 7952. doi: 10.1021/ja302178w

(83) Walker, W.; Giordani, V.; Uddin, J.; Bryantsev, V. S.; Chase, G. V.; Addison, D. J. Am. Chem. Soc. 2013, 135, 2076. doi: $10.1021 / \mathrm{ja} 311518 \mathrm{~s}$
(84) Allen, C. J.; Mukerjee, S.; Plichta, E. J.; Hendrickson, M. A.; Abraham, K. M. J. Phys. Chem. Lett. 2011, 2, 2420. doi: $10.1021 / \mathrm{jz} 201070 \mathrm{t}$

(85) Zhang, T.; Zhou, H. S. Angew. Chem. Int. Edit. 2012, 51, 11062. doi: 10.1002/anie.201204983

(86) Elia, G. A.; Hassoun, J.; Kwak, W. J.; Sun, Y. K.; Scrosati, B.; Mueller, F.; Bresser, D.; Passerini, S.; Oberhumer, P.; Tsiouvaras, N.; Reiter, J. Nano Lett. 2014, 14, 6572. doi: $10.1021 / \mathrm{n} 15031985$

(87) Soavi, F.; Monaco, S.; Mastragostino, M. J. Power Sources 2013, 224, 115. doi: 10.1016/j.jpowsour.2012.09.095

(88) Ara, M.; Meng, T. J.; Nazri, G. A.; Salley, S. O.; Ng, K. Y. S. J. Electrochem. Soc. 2014, 161, A1969. doi: 10.1149/ 2.0031414 jes

(89) Liu, Q. C.; Xu, J. J.; Yuan, S.; Chang, Z. W.; Xu, D.; Yin, Y. B.; Li, L.; Zhong, H. X.; Jiang, Y. S.; Yan, J. M.; Zhang, X. B. Adv. Mater. 2015, 27, 5241. doi: 10.1002/adma.201501490

(90) Jang, I. C.; Ida, S.; Ishihara, T. J. Electrochem. Soc. 2014, 161, A821.doi: 10.1149/2.087405jes

(91) Lee, D. J.; Lee, H.; Song, J.; Ryou, M. H.; Lee, Y. M.; Kim, H. T.; Park, J. K. Electrochem. Commun. 2014, 40, 45. doi: 10.1016/j.elecom.2013.12.022

(92) Shui, J. L.; Okasinski, J. S.; Kenesei, P.; Dobbs, H. A.; Zhao, D.; Almer, J. D.; Liu, D. J. Nat. Commun. 2013, 4. doi: 10.1038/ ncomms 3255

(93) Hassoun, J.; Jung, H. G.; Lee, D. J.; Park, J. B.; Amine, K.; Sun, Y. K.; Scrosati, B. Nano Lett. 2012, 12, 5775. doi: 10.1021/ nl303087j 